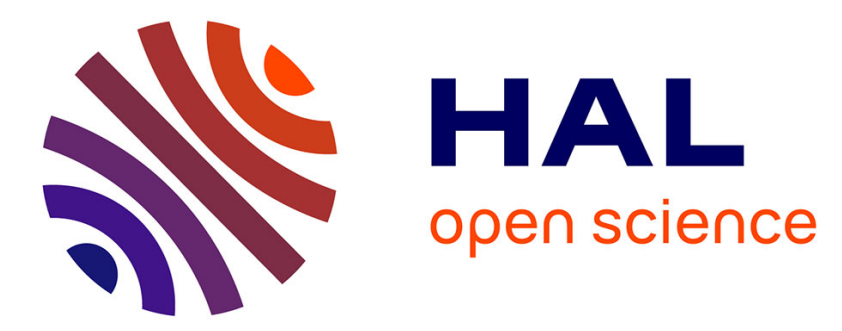

\title{
Great Expectations. Hicks on Expectations from Theory of Wages (1932) to Value and Capital (1939)
}

\author{
Jean-Sébastien Lenfant
}

\section{To cite this version:}

Jean-Sébastien Lenfant. Great Expectations. Hicks on Expectations from Theory of Wages (1932) to Value and Capital (1939). 2020. hal-03183464

\author{
HAL Id: hal-03183464 \\ https://hal.science/hal-03183464 \\ Preprint submitted on 27 Mar 2021
}

HAL is a multi-disciplinary open access archive for the deposit and dissemination of scientific research documents, whether they are published or not. The documents may come from teaching and research institutions in France or abroad, or from public or private research centers.
L'archive ouverte pluridisciplinaire HAL, est destinée au dépôt et à la diffusion de documents scientifiques de niveau recherche, publiés ou non, émanant des établissements d'enseignement et de recherche français ou étrangers, des laboratoires publics ou privés.

\section{(ㅇ)(1) $\$$}

Distributed under a Creative Commons Attribution - NonCommercial - NoDerivatives| 4.0 
This article is a preprint (accepted) version of an article to be published in Revue d'économie politique. There may be some slight differences between this text and the one to be published.

To cite this document:

Lenfant, Jean-Sébastien. 2020. Great Expectations. Hicks on expectations from Theory of Wages (1932) to Value and Capital (1939), Revue d'économie politique (forthcoming 2021)

\title{
Great Expectations. Hicks on expectations from Theory of Wages (1932) to Value and Capital (1939)
}

\author{
Jean-Sébastien Lenfant \\ Université de Lille, Clersé
}

\begin{abstract}
The article is intended as an in-depth study of the development and role of expectations within John R. Hicks' representation of the functioning of a capitalist economy. It covers his contributions to economic theory in the 1930s, with a particular focus on Value and Capital. The question underlying the study is whether Hicks develops a theory of expectations. We argue that there are several elements of such a theory in Hicks's work, though what is most important to him is the historical dynamic generated by heterogeneity of expectations.
\end{abstract}

Key-words: Hicks (john Richard), expectations, temporary equilibrium, stability, cycles.

\section{Résumé}

L'article explore en détail le développement et le rôle des anticipations dans la représentation du fonctionnement d'une économie capitaliste selon John Hicks. Il couvre ses contributions à la théorie économique dans les années, 1930, avec un accent sur Valeur et Capitali. La question posée est de savoir si Hicks propose une théorie des anticipations. Nous soutenons qu'il y a plusieurs éléments d'une telle théorie dans les écrits de Hicks, mais que ce qui est le plus important pour lui est la dynamique historique générée par l'hétérogénéité des anticipations.

Mots-clés: Hicks (John Richard), anticipations, équilibre temporaire, stabilité, cycles 
"Uncertainty and expectations are the joys of life"

(Congreve, Love for love (1695), quoted by Hicks $(1939,191)$ )

\section{Introduction ${ }^{1}$}

Value and Capital (1939) (hereafter VC) is a landmark both in the history of general equilibrium theory and in the history of macroeconomics. Indeed, after the success of "Mr. Hicks and the Classics" (Hicks, 1937), Hicks conceived of construing a general equilibrium framework that could be used to model the dynamic of an economic system through time, allowing for trade cycles and some Keynesian results such as lasting unemployment in some specific cases. Lerner $(1940,305)$ aptly summarized this: "Professor Hicks suffers from an urge to be more general than General Theory, even if the struggle to be different prevents him from being more Keynesian than Keynes"

Hicks' project of building a general equilibrium representation of an economy which would work as a fully-fledged device to think about employment, money, capital accumulation, beyond the usual assumptions of a stationary state equilibrium (or a steady state), makes of Value and Capital his most important achievement, his "masterpiece" (Hahn, 1990, 543). To Hicks, the general equilibrium approach is primarily a discipline for theoretical thinking about the many complex direct and indirect effects that key economic variables would have on agent's decisions. At the same time, it is the economist responsibility not to get lost in the flux of behavioural combinations that he creates and to highlight what set would most likely be operating in the economy at some point in time, or through time. Several commentators have identified this method of approach. To Hahn $(1990,539)$ it is in tune with a "recognisable British tradition”, while Amyia Kumar Dasgupta $(1972,2315)$ points to the art of being-as Wicksell was - an "eclectic ... a grand synthesizer in whose hands the system that he builds on assumes new and immensely heightened significance". I would uphold that there is a more personal touch in it, a Hick's touch. As far as it stands in Value and Capital, one could say that there is a definite aim at making the general equilibrium approach theoretically operational (Lenfant and Lallement, 2004; Rubin, 2011, Béraud, 2014), i.e. providing the theorist with tools to analyse the temporal path of actual economic systems, without for all that furnishing practically operational (measurable) tools to do it. Hicks's theory was more a tool to be used as a framework for economic history that for econometric application.

To do this, Hicks' challenge in Value and Capital is to reconcile within a single theoretical framework the static general equilibrium of Walras ([1874-1877] 1988) with the theoretical account of capital accumulation and the possibility of a neutral money of Wicksell ([1898] 1936) (Interest and Prices). ${ }^{2}$ This endeavour, however, would also bear the methodological marking of Pareto and Marshall, with a bias in favour of the latter (VC, 3). The key notions at the core of Hicks' analytical achievement are well known. It all revolves around the conception of dynamic as a succession of short-term temporary equilibria, all linked together through the confrontation of past decisions and the building of new plans from period to period. More precisely, past decisions and new plans are encompassed under the heading of expectations. They establish a link between, on the one side, previous plans and expectations of each agent in the economy and, on the other side, their new plans and expectations once a new provisional (temporary) equilibrium has been reached (or simultaneously with its establishment). Thus, the

\footnotetext{
1 Paper presented at the First nHice Workshop (network for the History of contemporary economics) "Expectations: Old Debates and New Considerations", 26th-27th November 2014, University of Nice-Sophia Antipolis. I am indebted to the participants for comments, with special mention to Jean-Luc Gaffard for his suggestions. I also thank two anonymous referees for their precious recommendations and Muriel Dal Pont Legrand for her continuous support. The usual caveat applies.

${ }^{2}$ Note also that Hicks had supervised the English translation of Lectures on political economy (Vorlesungen über Nationalökonomie, 1901 and 1906), published in 1934 and 1935 (Wicksell [1901-1906] 1934-1935).
} 
notions of Temporary Equilibrium and Expectations are two complementary essential components of Value and Capital. While the notion of Temporary Equilibrium has received much theoretical critical attention (Grandmont, 1977; Ingrao and Israel, 1990, chap. 8; De Vroey, 2006; Hahn, 1990; Glasner, 2018), the treatment of expectations in Value and Capitaland in previous works by Hicks - is a neglected subject.

Clearly, the common view is that Hicks was aware that most of his theoretical achievement would depend on his treatment of expectations even though he fell short of developing a satisfactory theory of expectations (Lachmann, 1946; Hahn, 1990; Dasgupta, 1972; Leijonhufvud, 1984; Bliss, 2008; Rubin, 2011). We shall deviate slightly from this common view. The reader of Value and Capital may justifiably feel that the treatment of expectations is unduly limited, reducing expectations to a simple measurable index: elasticity of expectations. Hicks would later deplore the success of this notion that opens to a purely mechanistic and static kind of analysis (Hicks, 1985, 87). In contrast, several passages of the book and previous articles show that to Hicks, expectations are an essential feature of economics, and we would say, a founding stone of Hicks' views about economics as a temporal process. It is the purpose of the present article to go beyond the elasticity of expectations tool to identify how Hicks would deal with expectations in Value and Capital and to confront it with Hick's own previous attempt at dealing with expectations in the 1930s. In a few words, our stance is that one's judgment about Hicks and expectations depends partly on what one is awaiting as a theory of expectations. Clearly, Hicks does not provide a general statement of how people-rational individuals - are forming their expectations of prices and interest rates, or any other kinds of expectations. Even less does he pretend to provide a general model of them. However, Hicks provides several statements relatively to the spreading of expectations among agents, and builds on this several intuitions regarding the dynamic path of an economy, especially its fluctuations and risks of breakdown. The article discusses Hicks's views about expectations, and claims that it needs to be understood within a specific conception of the microfoundations of macroeconomics, in which heterogeneity of agent's behaviours and relations to risk are essential to understand and model economic phenomena.

The celebrated notion of elasticity of expectations only appears late in Value and Capital, and it is used as one element in the whole mechanics erected by Hicks to analyse the dynamic of a general equilibrium. The use of the concept is linked with two aspects of the whole analytical system: (i) the analysis of stability of a system of interrelated markets, (ii) the notion of temporary equilibrium. The notion of elasticity of expectations and the set of assumptions about them is used, above all, as a way to tell different stories about the dynamic of the model. This state of affairs was already underlined by Lachmann.

\footnotetext{
"In creating the concept, Professor Hicks has provided us with a convenient criterion of classification of the modes of a relationship, which we can use even though we may know nothing about the causes and conditions of the various modes." (Lachmann, 1945, 248)
}

Following Lachmann's appraisal, a hurried reader will get the impression that Hicks contents himself with a general pattern of expectations, without further questioning the formation of expectations. Our view is that given the new challenge that Hicks addressed himself to deal with dynamic stability and the trade cycle, he had to keep the analysis of expectations to a minimum, to subject his analysis to the modelling strategy associated with the Temporary Equilibrium framework. For all that, it would certainly be a mistake to think that Hicks did not assign any more importance to expectations. Quite the contrary. Value and Capital contains several passages in which expectations are discussed for their own sake, and Hicks' previous works in the 1930s show that expectations are an essential element to his understanding of the features of a capitalist economy. Taking account of this very fact that the treatment of 
expectations is partly dependent on the whole apparatus erected by Hicks to think about stability in a dynamic environment, we hope to reinstate the meaning of expectations within the boundaries of his project and methodological spirit.

A single article of standard length could not account for the sophisticated structure of Value and Capital. The complexity above all—and mathematical weaknesses — are the main reasons why the book did not actually serve as a sound analytical starting point for further developments in general equilibrium modelling and Keynesian macroeconomics, despite a few followers (Metzler, Mosak, Lange, Patinkin). For all that, Value and Capital is an impressive book, containing lasting intuitions and a wealth of contributions to the toolbox of neoclassical theory (e.g. substitutability and complementarity, surplus and rent, temporary equilibrium, elasticity of expectations, theory of money and interest, concept of income). It would be useless to embark in a study of expectations and their role in Value and Capital without having first an overview of what Hicks intended to do and - most importantly — of the theoretical style of reasoning that constitutes his sole methodological credo. In this respect, expectations will turn out to be a methodological device that permits the use in dynamics of results established in the field of static analysis, viz. the case of an imperfectly stable system. It is with this device in mind, which is a key element to think about Keynes' General Theory as "the economics of depression" (Hicks, 1937, 155), that an analysis of expectations becomes necessary (Rubin, 2011). While Hicks' works in the 1930s show that expectations (and their relations to time, risk or uncertainty) are an essential point of contention with other economists (either at LSE or at Cambridge), Value and Capital reveals the challenge of integrating them into the theory of value.

Value and Capital represents an original accomplishment of Hicks' impressive effort to conflate in a single system a concern for the understanding of the properties of capitalist economies through time and a theoretical account of the whole economic system based on a theory of choice. Hicks would not follow this theoretical project after WWII, focusing more and more on alternative ways to deal with time, capital and money, in which expectations were to play a minor role. Therefore, our investigation in this article will not go beyond Value and Capital. ${ }^{3}$ Hicks himself would criticize the Temporary Equilibrium device as inadequate to deal with sequential analysis in a satisfactory way. "In this equilibrium prices and price expectations are, at least to some extent, reciprocally determined. Such reciprocal determination is, however, a piece of telescoping; in dynamic analysis telescoping is dangerous" (Hicks, 1985, 70)

The remainder of the article is as follows. Section 2 presents Hicks' views on expectations in various works prior to Value and Capital. It shows that expectations are essential to Hicks's understanding of the functioning of a capitalist economy. Section 3 presents the structure and discursive logic of Value and Capital and clarifies Hicks' goals regarding expectations. Section 4 concentrates on the notions of Temporary Equilibrium and Elasticity of expectations and how they are used in Value and Capital. Section 5 concludes and provides some insights on what, if ever, could be a theory of expectations in Value and Capital.

\section{Going beyond the stationary state: a plea for introducing expectations in economics}

\footnotetext{
3 Capital and Time. A Neo-Austrian Theory (1973) introduces a study of the sequential path from one equilibrium to another equilibrium. It is based on the assumption of static expectations throughout (Hicks, 1973, 110)

4"In this equilibrium prices and price expectations are, at least to some extent, reciprocally determined. Such reciprocal determination is, however, a piece of telescoping; in dynamic analysis telescoping is dangerous" (Hicks, $1985,70)$
} 
Among neoclassical economists, Hicks is certainly not the first one to consider that agent's expectations (especially producers) are important to a theory of economic equilibrium. In many respects, his work borrows to Marshall, Wicksell and the Swedish school (see below) and probably also to an older tradition of analysis of crises going back to John Stuart Mill and Jevons (Peart, 1991). Notably, Marshall's analysis of the producer's behaviour in Principles of economics relies on price expectations, and he deals with them again in Industry and Trade (Wolfe, 1956; Kregel, 1977). Wicksell's cumulative processes point to entrepreneurs' extrapolative expectations of inflations as creating inflation (Boianovsky and Trautwein, 2006, 177). However, both authors tended to downplay the role of expectations as a pivotal theoretical subject. The dominating view, as Hicks himself would soon realize, is that of the stationary state, in which having expectations proves innocuous to the theoretical outcome. In contrast, Hicks would introduce a principle of deviations from the stationary state as an essential feature of modern capitalist economies, calling for a theory of agents' behaviour when they are not involved in a routinized stationary process.

\subsection{The theory of wages (1932)}

Hicks' interest for expectations appears in his first major contribution to economics, The Theory of Wages, a book that owes much to the intellectual climate fostered by Lionel Robbins at the LSE (Hicks, 1973). In an environment of uncertainty, the functioning of the labour market will prove very different from other markets, since both workers and entrepreneurs will have to consider the costs associated to any new contract (a change of occupation for a worker, a change in the methods or organisation for the entrepreneur). In equilibrium analysis, one commonly assumes that market forces tend to reduce those costs to a minimum, particularly in a stationary state. In this case the calculus of benefits and costs that accrue to each agent is easily done. The same kind of assumption permeates the usual description of the equilibrium path when there is a steady state or the environment is uncertain. Hicks departs from this common assumption by pointing out that it hinges on the false representation that the economic system jumps from one equilibrium to another, thus ignoring that this change in equilibrium depends on agents' appraisal of it and their reaction to it. This first instance of expectations in Hicks' work, then, is linked with a question of modelling the path from one equilibrium position to another. Hicks rejects the usual assumptions that when a change occurs, it shall be taken passively as a change from one stationary state to another stationary state, and that costs and benefits of changes to individuals should be calculated over such an assumption that the new situation attained will prevail in the long-run. Thus, because agents have, from past experience, no reason to think that any current situation is bound to remain unchanged, their individual calculus regarding the costs and benefits from any new situation (professional or entrepreneurial) are valued through a short term calculus. It is the essence of any capitalist economy to make agents myopic calculators, because they cannot foresee long run prospects. It is remarkable that already in 1932, Hicks points out that the reason why agents will not calculate over an indefinite temporal horizon stems from their perception that a market is not in equilibrium or, more precisely, from the fact that any equilibrium is at best temporary (yet, the word "temporary" does not appear in 1932). And this, in effect, becomes true as soon as agents choose to behave within a finite horizon. To Hicks, this is enough to make agents understand that their common sphere of expectations and decisions has an upper bound. In retrospect, the following long quotation from The Theory of Wages seems programmatic and helps thinking about Hicks' balanced attitude towards Austrian and Keynesian theory as related to his own views about uncertainty and expectations.

"In fact, everyone does foresee changes to some extent, and the effects of a change differ, according as it is expected to continue or not. Suppose an entrepreneur receives 
a sudden increase in orders. This may mean any one of four things: (1) It may mean merely that ordinary orders have been brought forward, so that the exceptionally great demand of today will be matched by an exceptionally low demand at some future date; (2) it may be a special demand for some special non-recurring purpose, so that after it has been met demand will return to normal; (3) it may be an indication that demand will henceforth settle down to a new and higher level; (4) It may mean the beginning of an expansion, so that demand will not only maintain the new level, but rise above it. It may mean any one of these four things, and it will be met in a profoundly different manner according as it is interpreted to mean one or another of them." (Hicks, 1932, 59-60)

This quotation deserves some additional comments about time and expectations.

Firstly, once agents perceive uncertainty, they have no reason to regard a situation as stable, hence their modes of behaviour must change and they will shrink voluntarily their calculus horizon and recognize that foresight has many more consequences on their situation that it would have otherwise.

Secondly, Hicks also introduces the very idea that the type of expectation determines the economic outcome, hence the property of a future situation to be an equilibrium or to remain a stable equilibrium. Hicks does not venture too far in this direction. Agents do have expectations, but they do not reflect on the effect of their own expectations (and that of others) on the economic outcome, a critical point that would surface later on.

Thirdly, the four cases above are exactly describing the notion of elasticity of expectations as it would be developed in Value and Capital. Here, what counts is that a current change from a past price to a current price is interpreted in various ways. It presents the full content of the analysis of the formation of expectations in The Theory of Wages. For instance, Hicks does not ponder whether those various reactions are motivated one way or another by some specific piece of information or belief, and he seems to be content with the strict description of price expectations as a simple function of the current and past prices. ${ }^{5}$

Theory of Wages offers then a final paragraph on the consequences of agents' actions on the future equilibria. It opens to a reflexive view of expectations.

\begin{abstract}
"Further, the effects of today's actions are not ended today; and action is always liable to be influenced by the remoter consequences which are expected to flow from it. But the importance attached to these remoter consequences depends on what the situation is expected to be in which they materialise; and thus any action depends on all the consequences which are expected to flow from it, and also on general expectations of the relevant future. Neither can be foreseen perfectly; but both can be foreseen to some extent, and both must be allowed for." (Hicks, 1932, 60)
\end{abstract}

Hicks does not develop his thoughts much ahead, and we must be content with the idea put forth that the stationary equilibrium framework cannot account for the uncertainty of individual calculus in an ever changing environment. So we must interpret Hicks's view as meaning simply that the consequences of an action (taking over a new job, facing a new method of production) are valued differently according to the various price expectations (wages, costs of learning, non-tradable costs, training costs, selling price, consumer price index) and non-price expectations (the "situation") which, taken as a whole, represent the relevant (new) data-to be added to preferences and technology - to characterize an economic environment. The non-price consequences (the set of actions that will have to be undertaken or the changes in the choice set) as well as the prices that are relevant to value those actions, cannot be foreseen "perfectly".

\footnotetext{
${ }^{5}$ Of course, since the meaning of the past price is not precisely defined, it can be taken as an average of past prices (over some periods) as well as the expected price can be interpreted as an average of future prices over some future periods (Arrow and Nerlove, 1958). We discuss this interpretation later on. Besides, this interpretation simplifies the calculus of discounted costs and benefits to agents.
} 
Hence, Hicks assumes that some probabilities can be attributed to those various elements, and actually are (a stance explicitly upheld in Hicks (1931)). We may venture to add that to Hicks, the fact that people know that they will be able to settle new contracts in the short run, when their views about the future will have changed too, is a reason why they do make probabilistic calculations about the future. Calculations made on the basis of those expectations are likely to be sensitive to changes in expectations. Even if Hicks would not develop his analysis of expectations along these lines, it is certainly important to explain his rebuttal of the stationary state as a sterile modelling practice, unable to offer a satisfactory explanation of economic phenomena. The same kind of argument would be repeated in his theory of money (Hicks, 1935a) and in Value and Capital.

On another occasion, in The Theory of Wages, Hicks discusses the consequences of a wage regulation imposing a minimum wage rate higher than the competitive wage (chapters IX and $\mathrm{X}$ ). After considering the effect of this increase on the distribution of income, thus on the various productive sectors, and the indirect effects of reallocations on capital intensive industries, he wonders what could be in the end a new equilibrium. The main idea is that capitalists who receive less, are tempted to reduce their savings, and the consequential increase of the rate of interest is to destroy even more capital (not to renew the used equipment), hence reaching an equilibrium becomes harder. Instead of being found at once, the final equilibrium can be approached through a cumulative process. The length of this process of decline is aggravated by interconnectedness between sectors, by the existence of an unemployment benefit system, and by "the series of disappointed expectations which must almost inevitably mark its course." (Hicks, 1932, 201). During this process, "faulty anticipations" are responsible for a greater loss of capital, since some new investments will still appear profitable that will prove worthless in the end, "when the disease has gone further" (Hicks, ibid.).

\section{2 "Disequilibrium is the disappointment of expectations"}

During the 1932 - 1937 period, Hicks would build step-by-step theoretical building blocks towards a general theory of the economy, in which the complexity of interrelated markets is accounted for while a number of still debated theoretical subjects - capital and money-would be adequately integrated into the analysis. This subsection aims at providing an overview of how Hicks would elaborate his insights about capital, money, dynamics, and how expectations are accounted for at each step.

"Equilibrium and the trade Cycle" (Hicks, [1933] 1980), originally published in German in 1933, can be read as an original stance on the part of Hicks on the modelling of dynamic, money and capital. In those years of high theory, several original contributions fostered heated debates. On the one hand, there is Keynes views on money and the cycles in A Treatise on Money (Keynes, 1930). On the other hand, there is the Austrian interpretation of capital, equilibrium and cycles, as exposed by Hayek in 1928 and in the famous series of conferences at the LSE, issued shortly after as Prices and Production (1931). Hicks' article is in several respects a declaration of independence towards both lines of thought on the treatment of dynamic and money.

Hicks' aim is to question the use of the concept of equilibrium in the theories of the cycles, especially when monetary phenomena are accounted in the fluctuation mechanism. The issue is thus about the possibility to integrate money into the general equilibrium approach of the Lausanne school. Hicks rejects the static view of equilibrium associated to Walras and Pareto. Fundamentally, to Hicks, the static notion of equilibrium makes sense in the Lausanne school 
approach if it is already treated as part of a dynamic problem. ${ }^{6}$ Unfortunately, such an understanding of the equilibrium is adapted only to describe a stationary equilibrium and is unfit to an evolving economic system with net saving. ${ }^{7}$ Hence, the concept of equilibrium cannot offer a valuable description of reality. One possible extension is that of the intertemporal perfect foresight equilibrium of Hayek (1928). This concept of perfect foresight equilibrium can serve at best as a benchmark to think of situations that are of interest to economists. "A real economy is always in disequilibrium" (ibid.), and it is the duty of the economists to think first of the main causes (and only them) that can explain cyclical fluctuations through a general effect on prices: the rate of interest and the value of money (Hicks, 1933, 527).

Developing his thoughts along this line, Hicks discards Hayek's views on money and monetary policy. The main motive for money demand is ignorance of the future, imperfect foresight; it is a disequilibrium phenomenon in a risky environment, affecting the value of velocity of circulation. The origin of cycles is to be found in changes of economic data (through changes in foresight and monetary behaviour), and it is bound to affect any economic system. Contrary to laissez-faire views, a banking monopoly may prove useful to alleviate monetary effects of the trade cycle by controlling the velocity of circulation, though its control shall prove impossible.

Holding money rather than other more or less risky assets depends on the overall confidence that agents have in the future. Here, as in the Theory of wages, a cumulative process of sales and losses through time can take place, due to speculative behaviours (any anticipation of price fall of securities and long term capital assets would generate sales that in turn spread the losses and the shortage of capital supply and deteriorate confidence) (Hicks, [1933] 1980, 530). Broadly, the rest of the paper analyses the mechanisms that lead to depression, recovery and boom, mixing arguments from Hayek and Keynes, in tune with the context of preoccupations with deflationary spirals of the time. ${ }^{8}$ Hicks' departure from the Hayek view is that "Imperfect Foresight" is the fundamental reason for explaining crises, depressions, recoveries and booms, while the properties of the means of payment (being or not a good with a monetary use) are of secondary importance.

\subsection{A Suggestion for Simplifying the Theory of Money}

"A suggestion for Simplifying the Theory of Money" (Hicks, 1935a) complements Hick's elements of analysis of the trade cycle. It is important in that it establishes clearly Hicks' theoretical goal of treating individuals' behaviours about money in accordance with the theory of choice (Pareto and Wicksteed), to make sense of it according to the law that the relative value of two commodities reflect their relative marginal utilities. Various attempts at getting out of the quantitative theory and thinking about money in marginal terms are unsatisfactory

\footnotetext{
${ }^{6}$ Hicks' alternative interpretation of the static equilibrium along a Edgeworth-Marshall device implies that one should consider (i) a process of price variations with an influence on the final equilibrium reached (except under a Marshallian assumption of absence of income effects in the process) or (ii) an Edgeworth recontracting device, with a known date of end at which individual contracts are binding. In both cases, time enters into the device.

7 Apparently, Hicks thought it to be impossible because he did not discuss the possibility of a continuing adaptation of the labour force (in quantity and abilities) to accompany such an evolution. Of course, since such assumptions are seldom realized, Hicks foregoing argument is unaffected.

${ }^{8}$ As noted previously, the idea of founding cycles on faulty expectations can be traced back to Mill, is used also by Jevons, Marshall. Fisher would also build on them in The Purchasing Power of Money (Fisher [1911] 1913) and "The Debt Deflation Theory of Great Depressions" (Fisher, 1933). It is also in tune with the Stockholm School advances on expectations and macrodynamics (see Laidler, 1999). It is not the purpose of this article to delve into the specificities of each author, nor to clear up the hank of influences. This would make enough for a single article. Be it enough to indicate, though, that Hicks does not explicitly refer either to Fisher or to Hayek in Value and Capital.
} 
(Wicksell, Mises, Marshall). Fundamentally, Hicks links this with an inability to make allowances for expectations in the theory of money demand, thus overlooking that element of uncertainty which makes the valuation of "real balances" indeterminate (Hicks, 1935a, 2, fn1). ${ }^{9}$ A marginal theory of money starts with Keynes' theory of the liquidity preference (Keynes' "third" theory as Hicks calls it) already referred to in 1933, stating that the "price-level [of investment goods] depends upon the relative preference of the investor-to hold bank-deposits or to hold securities. ... Here at last we have a choice at the margin!" (Hicks, 1935a, 3). These preferences depends upon the relative desire of the public for liquidity or profit ("bearishness" or "bullishness" in Keynes' words). ${ }^{10}$

Applying the theory of choice to "preference for liquidity" necessitates to make due allowances for expectations. A leading idea again is that economic life being essentially influenced by expectations and their consequences, monetary arbitrages are likely to occur at any moment, with two consequences. The usual link between money demand and income is actually loose and only indirect; it can lead to cumulative effects. On the one hand, from a purely static perspective, money demand will depend upon the risk and yield perception on the portfolio of more or less liquid assets held by individuals (based also on their perception of the reputation of debtors). On the other hand, within a comparative statics perspective-e.g. following an increase in wealth ("expected income") due to a rise in the value of an asset-it will depend upon the way this initial unexpected price rise will in turn change expectations about future prices and yields (hence changing the risk parameters). As a result of changes in expectations, surrounded with "a certain penumbra of doubt" (Hicks, 1935a, 7) there is no more any simple relationship between wealth and demand for money.

Thus, we can see that already in 1935, expectations play an essential role in Hicks' theory. We are then swept along in an unstable sequence of price-expectations and money holdings, which must be checked somehow within fluctuations. To provide a rationale for a more realistic profile, Hicks relies on the idea that members of the community, having different wealth levels, will not adapt their expectations the same way. Poor households will not be induced to reduce their money holdings in favourable circumstances. ${ }^{11}$ Their insensitive behaviour prevents the system from being too much unstable (flying into exaggerated optimism or pessimism) as against the destabilizing behaviour of sensitive traders.

This way of analysing the properties of a system through group-differentiated behavioural assumptions is operative in Hicks's theory of money, and announces a mode of reasoning and arguing that will become frequent in Value and Capital. Also, Hicks considers that a theory of the formation of expectations is hopeless, being too loosely linked with psychological variables that are disconnected from objective facts. "Applying monetary theory... needs judgment and knowledge of business psychology much more than sustained logical reasoning." (Hick, 1935a, 14) If we are not to expect a theory of expectations, at least we can hope that the economist will take on the lead "once the connection between objective facts and anticipations has been made"

\footnotetext{
9 "We now realise that the marginal utility analysis is nothing else than a general theory of choice, which is applicable whenever the choice is between alternatives that are capable of quantitative expression. Now money is obviously capable of quantitative expression, and therefore the objection that money has no marginal utility must be wrong. People do choose to have money rather than other things, and therefore, in the relevant sense, money must have a marginal utility" (Hicks, 1935a, 3)

10 "The amount of money a person will desire to hold depends upon three factors: the dates at which he expects to make payments in the future, the cost of investment, and the expected rate of return on investment. The further ahead the future payments, the lower the cost of investment, and the higher the expected rate of return on invested capital the lower will be the demand for money." (Hicks, 1935a, 6-7).

${ }^{11}$ Hicks's statement of this case of heterogeneous behaviours is ambiguous, since he seems to assert that though they may have sensitive expectations, the less well-off shall not be sensitive to those changes, thus behaving in a rather routinized fashion instead of the rational wealthy investor. The only way to account for some rational behaviour, however, is by invoking the importance of "transaction costs" and "subjective costs" to the less wealthy.
} 
(ibid.). But this has to be done conditionally on "bring[ing] out very clearly the assumptions which we are making about the genesis of anticipations" (ibid.)

\subsection{Expectations and Stability}

The last important contribution somehow related with equilibrium and expectations before Value and Capital is "Wages and Interest: The Dynamic Problem" (Hicks, 1935b). After rejecting both the "factor of production" perspective (J. B. Clark, Knight) and the "period of production" perspective as both timeless, Hicks wonders about a modelling strategy to handle a moving economy. It contains the first hints at the temporary equilibrium device. Hicks proposes "to cut up the varying flows into short sections, each of which can be treated as constant. We can do this by supposing changes to take place, not continuously, but at intervals" (Hicks, 1935b, 457). To Hicks, this is a legitimate and innocuous modelling strategy. Broadly, the article discusses the notion of capital within a fictional simplified nonmonetary economy in which Bread is the only consumption good and all exchange values are expressed in Bread units. Entrepreneurs and labourers produce Bread; assets and liabilities are expressed in Bread; the rate of interest is expressed in Bread (supplying so much Bread tomorrow against so much Bread today). Hicks introduces some elements of modelling of the dynamics, considering that transactions will take place discontinuously, say a Monday, while no transactions will take place the rest of the Week. On Monday, contracts are signed and (past) contracts are executed (quantity of labour hired, quantity of one week loans, and payment of labour). ${ }^{12}$

Two prices (rate of wages and rate of interest) are enough to define the equilibrium of this simplified economy (market for bread, loans and labour). Each agent's current behaviour (be there rentiers, labourers, entrepreneurs) is affected by anticipations of future values of interest rates and/or wage rates. Entrepreneurs make a production plan for the present and future periods and can choose to use labour now for producing bread in future periods. ${ }^{13}$ The plan of the entrepreneur is that one which maximises the present value of the net assets. The anticipated values of wage and interest determine both the discounted present value of net assets and the production plan. The anticipated rate of wages in any period must equal the marginal product of that labour in any subsequent period (discounted back to that period). The question is whether a simple change in the prices or price-anticipations (wages and interest) would change the optimal plan and how. Following his usual limit-case-study way of arguing, Hicks discusses four cases of change in current or expected future values of the wage and interest rates. A next step is to discuss how expectations are formed on the basis of current and past values. Here, Hicks's discussion is limited to providing a way to link time periods to one another.

\footnotetext{
"We have to recognise that the expectations of the future course of wages (and interest) are largely based on current rates; consequently a change in current rates is very unlikely to leave expected rates unchanged. When this is taken into account, we evidently ought to inquire what is the effect of a change in current wages (or interest) which induces a proportionate change in expected wages (or interest) in the same direction." (Hicks, 1935b, 463)
}

The details of the comparative statics of the model shall not retain us further. The main idea is that the stability of the model shall depend upon the swiftness of reaction of some category

\footnotetext{
${ }^{12}$ It is not clear whether labour is paid on the basis of the previous week contract or on the basis of the current Monday contract. Apparently, it is of no importance to Hicks. The labourer "receives a certain claim to bread on the first Monday (either in respect of past services or as an advance on future)" (Hicks, 1935b, 459)

${ }^{13}$ While he also mentions an increase of Equipment, this has to be interpreted as an increase of capital due to stocks.
} 
of agents in the system, which might depend in turn upon the sensitiveness of their expectations. Take for instance an initial increase in the wage rate. The receipts from labour are increased, hence demand for Bread will increase and the equilibrium on the bread market will be unchanged only if the demand on the part of entrepreneurs is reduced. Since the value of their assets (reckoned at the current price) is lowered, "on the basis of their present expectations, they will have to plan a reduction in consumption either now or in the future. If they are quick to adjust their consumption habits, they may choose to consume less now; in which case the total demand for bread may be unaffected. But if they are not quick, the total demand for bread will rise, and the rate of interest will rise to" (Hicks, 1935b, 466). This follows from a decrease of the amount of supply of loans on the part of the entrepreneurs.

As a provisional conclusion to this section, we can say that Hicks's contributions since the "first theoretical achievement" (Hicks, 1973) of The Theory of Wages put to the fore lasting ideas about the need to integrate dynamic within the framework of the theory of choice. I would even uphold that to Hicks, uncertainty and changes in our economic environment are two essential features that bear on agents' endeavour to behave rationally, making of expectations a key element to understand the evolution of economic processes.

Another complementary feature of Hicks' kind of theorizing is that economic explanations cannot rely exclusively on microeconomic behaviours. To account for economic dynamics, economists will have to consider also the socio-economic variables that characterise a situation, allowing for the heterogeneity in beliefs and expectations. ${ }^{14}$ It was left for Value and Capital to connect all those building blocks into a general equilibrium framework.

\section{From Static Equilibrium to Temporary Equilibrium and Dynamics: Thinking about expectations in Value and Capital}

In this section, I discuss the main purpose and methodological structure of Value and Capital, with special focus on the way expectations are brought to the fore with the aim of developing a dynamic general equilibrium model.

\subsection{A first look at the structure of Value and Capital}

As its title indicates, Value and Capital aims at unifying two main themes of inquiry: the theory of value and the theory of capital. Actually, this program is achieved in four steps, forming the four parts of the book. The first two parts deal mainly with the theory of value and stability of a static exchange and (then) production economy, while the last two parts focus on capital, interest, money and related issues of dynamics. While the first two parts deal with the legacy of Walras and Pareto, part 3 and 4 are immersed in Wicksellian themes of capital and interest and in the various strands of reflections that stem from them: Hayek, Keynes, and the Swedish School—Lindhal and Myrdal—which Hicks came to know in the early 1930s (Schackle, 1967; Hicks, 1973; Ingrao and Israel, 1990, ch.8). ${ }^{15}$ Precisely, part I deals with the theory of

\footnotetext{
${ }^{14}$ This echoes also Robbins' statement "The main postulate of the theory of dynamics is the fact that we are not certain regarding future scarcities" (Robbins, 1932, 79)

${ }^{15}$ It is beyond the goal of this article to examine the influences of the Swedes on Hicks' early theory of the dynamics (see Hansson, 1982). On various occasions, Hicks has mentioned his acquaintance with some contributions by Myrdal and Lindahl (published either in English or in German) (Hicks, 1979). Notably, he wrote a review (Hicks, 1934) of the book edited by Hayek in which Myrdal ([1927] 1933) discussed the concept of equilibrium for monetary theory ("Gleichgewichtsbegriff als Instrument der geldtheoretischen Analyse"). As for the place of expectations, Myrdal ([1927] 1933) delivered a rich discussion of this notion, and hinged on it to criticize Knight (1921); and Lindahl (1929), in his discussion of risk, was influenced by Keynes' Treatise on Probability (Keynes, 1921). In late accounts of his contributions, Hicks acknowledged that the Swedish school
} 
"subjective value" and consumer behaviour; part II sets out the properties of a static general equilibrium of exchange and production; part III presents the "foundations of dynamic economics", introducing capital, interest, money and the device of temporary equilibrium; part IV is devoted to the study of the "working of the dynamic system", notably through a discussion of its temporary equilibria and capital accumulation. Expectations enter the stage in part III and IV, together with the examination of capitalistic production as a time-using process.

Hicks devises Value and Capital as a unified work, providing its own tools of analysis and applying those tools step-by-step to a static system and then to a dynamic system representing an economy with consumption, production, capital and money. ${ }^{16}$ The culmination of all this is a concluding and sketchy chapter on economic cycles (chapter XXIV). Apart from this theoretical challenge, it is hardly doubtful that another goal of the book is to clarify Keynesian views regarding the dynamics of an economy and the possibility of a sustained disequilibrium, characterizing Keynes's "economics of depression" (Hicks, 1936 and 1937). ${ }^{17}$ To that aim, expectations are of utmost importance (Rubin, 2011).

A closer look at Hicks' own words about the logical connection between the static and dynamic is worth its while. Hicks insists on the idea that only the last part (part IV) deals with really important matters: the theory of capital and the dynamic of a pure capitalist economy. To that extent, the reader is inclined to figure out that the content of the first three parts is only a matter of methodological construction, a technical device for treating intricate problems that arouse with capital theory. In part II, Hicks provides a theory of general equilibrium of competitive markets for producers and consumers, by which factors of production and goods can be valued, with the idea that the laws of this general equilibrium can be studied separately from the problems arising once one takes into account the market for capital goods. Part III is a first exposition of the concepts and problems that appear once the capital market is introduced into the picture. It contains, broadly, the analysis of the temporary equilibrium, of expectations, of interest and money. Eventually, part IV is an analysis of a dynamic capitalist economy; it is based mainly on the use of the criteria of elasticity of expectations in a comparative statics reasoning, which is applied under various combinations of assumptions.

From a purely conceptual point of view, Hicks announces a property of the temporary equilibrium device, which is to draw a demarcation between what happens within a single period of time, for which the "static" theory is relevant, and what happens within successive periods of time, broadly the capitalist process of accumulation, for which the "dynamic" theory is relevant. The only way to warrant such a separation is that the laws of the "static" theory do not interfere with the dynamic process, and that conversely, the laws of the static system are immune from any pathological behaviour of the dynamics. This is something that we should keep in mind in our appraisal of the analysis of expectations and price movements in the temporary equilibrium device. I would like to stress that Hicks' stance regarding this separation between a so-called short term static period and a typically dynamic phase is not quite clear, and the proper role of expectations in this setting is not clear either. The reader may think at first that expectations are to be given full recognition in the dynamic part of the analysis, when the confrontation between production capacities and individuals' plans lead to further adjustments. Things will prove more complex and moving as the length of the Temporary

(particularly Myrdal's monetary equilibrium) had been his main source of inspiration to build the temporary equilibrium as a short term situation in which expectations are data. (Hicks, 1973, 8). Fontana $(2004,75)$ points out that both Hicks and Keynes had exchanges with Lindahl after he had developed a first draft of his "The dynamic approach to economic theory" (Lindahl, 1939)

16 "Our present task may therefore be expressed in historical terms as follows. We have to reconsider the value theory of Pareto, and then to apply this improved value theory to those dynamic problems of capital which Wicksell could not reach with the tools at his command" (Hicks, 1939, 3).

17 "The latter half of this book would have been very different if I had not had the General Theory at my disposal when writing. The final chapters of Part IV, in particular, are very Keynesian.” (Hicks, 1939, 4) 
Equilibrium short term period is moving itself. At present, Hicks would like the reader to take this demarcation just as a neutral technical device and not as a theoretical principle.

\begin{abstract}
I expect that these parts of our investigations (contained in Part III and IV) will seem to most readers the most interesting, as they are certainly the most important. ... It is the peculiar characteristic of our theory of capital that it depends upon our improved theory of value. The problems of capital and interest present, in fact, two sorts of complications: one is the complication proper to dynamic problems as such, but the other is simply the complication of interrelated markets, which can be dealt with separately. (VC, 5)
\end{abstract}

At the same time he is promoting a demarcation, Hicks points to the aim of synthesizing the knowledge obtained from each separate analysis, achieving a complete theory in which the static and dynamic analysis complete each other. Even though the complications due to interrelated markets are deemed "essentially irrelevant" (VC, 5), it is also said "the most important problems - where we have to face both the dynamic complication and the complications of interrelated markets, will finally be dealt with in Part IV." (VC, 5)

So, Hicks is balancing between two lines of thought. According to the first line of thought, he would stress the methodological devices that allow a separate treatment of "static" general equilibrium, that is, "a formal theory of the interrelation of markets" (VC, 6) (part II - General Equilibrium) and a more specific theory of capital markets (part III - The Foundations of Dynamic Economics). ${ }^{18}$ According to the second line of thought, he would stress the complementarity of the static and dynamic analysis for a complete analysis of a capitalist economy, the "Economic Process in Time" (VC, 6) (part IV - The Working of the Dynamic System):

Consequently, General equilibrium is not by itself a unifying method, contrarily to what Hicks was saying at the beginning, because it is split between a theory of production and consumption on the one side and a theory of capital and money on the other. The idea of a separation is not simply a result of the application of the method; it is given from the outset as a device to deal with time. Then the question that arises is what is behind the cross of strands? The conjecture here is that Hicks' analysis of expectations will deliver some clues about Hicks' attempt at integrating dynamics and statics, illuminating the proper role of expectations in this overall project, and maybe also the kind of expectations at stake at each step of a dynamic process.

\title{
3.2. A summary of the static theory of value
}

A brief inquiry into the main analytical innovations linked with the functioning of markets and their properties will help understanding the role of General Equilibrium as a method of inquiry in Value and Capital.

The first part of the book is a now classic exposition of the modern theory of demand and supply in an exchange economy, based upon "ordinal utility" and indifference curves. Starting from the Marshallian theory of value, Hicks provides a rational reconstruction of how this theory was progressively superseded by a modern theory based on indifference curves. He exposes the new theory of the consumer-based on Hicks and Allen $(1934)^{19}$ and discusses the relative importance of substitution and income effects. He argues that income effects are usually small when the budget share for the good is small. Therefore, in general, the substitution effect captures the largest part of the effect of a price change upon demand. Hicks concludes that after all, the Marshallian hypothesis of constant marginal utility of money and its implications - a

\footnotetext{
18 "If [part II] is regarded as no more than a formal theory of the interrelation of markets, it has its uses. That is how I wish it to be regarded here" (Hicks, 1939, 6)

${ }^{19}$ On Hicks and Allen (1934) joint contribution in historical perspective, see Chipman and Lenfant (2002)
} 
zero income effect - are valuable simplifications in some cases (VC, 27). He then proceeds to discussing aggregate income and substitution effects. On the aggregate, it must be stressed that the income effect will be a sum of positive as well as negative terms, depending upon whether goods are inferior or not to different consumers at this price. On the contrary, all substitution effects will go in the same direction. It tends to reinforce the idea that the substitution effect tends to represent the largest part of the total effect; hence that a reasonable method of thought is to inquire first about the properties of a system of markets when income effects are nil (a symmetrical system) and to think of the possible deviations due to income effects as a second step. In the final analysis, Hicks stresses that the law of demand and the law of market demand hold in general.

As a connected result of the above analysis, Hicks tackles the question of the supply curve, not to a producer, but to anyone getting his income from the selling of goods, notably for workers selling work force against money wages. This is a necessary generalization for a general equilibrium model of production.

This presentation is all the more important as it will not be possible to neglect in general, the income effect relatively to supply of goods, given that generally few resources are the only source of income. "We shall therefore expect to find many cases in which the income effect is just as powerful as the substitution effect, or is dominant. We must conclude that a fall in the price of $X$ may either diminish its supply or increase it" (VC, 36)

The other important outcome of this first part of Value and Capital is about the theory of complementarity within a general equilibrium system. Hicks provides a new presentation of the theory he had developed with Allen, but instead of presenting the theory of complementarity among three goods, he considers the theory of complementarity among two goods and all other goods together as a composite commodity (or equivalently as money purchasing power). It is intended to work out the effect of a price change of $X$ on the other goods together, and on each good particularly, according as they are complementary or substitutes (in terms of preferences) with $X$. It would be much too long to present in detail the theory (see Lenfant, 2006). The main outcome is to arrive at a general typology of the interconnectedness between different markets, which will be used to discuss stability in part II and "can be usefully applied to a variety of problems." (VC, 50)

Part II of Value and Capital, deals with the working of a static system of general equilibrium, restating the Walrasian analysis of stability and comparative statics. This analysis is grounded on the new theory of demand, especially on the typology of substitutability derived from it. In Hicks's view, there is no doubt that the law of supply and demand leads the economy to a stable equilibrium and that comparative statics results can be worked out. In a nutshell, Hicks' analysis is built on the idea that comparative statics results can be usefully applied to think of a set of interrelated markets (Bliss, 2005 and 2008). Hicks' analysis of stability is built on the properties of the optimal choice of the consumer. It is well known that Hicks' analysis revolves around a distinction between two kinds of stability, namely between perfect and imperfect stability. A case of perfect stability means that each individual market will react to a shift in prices through a decreasing excess demand (ceteris paribus). A case of imperfect stability happens when locally, a market (say for good $X$ ) does not exhibit a decreasing excess demand (it is not stable by itself) or becomes increasing through some reactions from other markets, but will soon be stabilized once backward effects of all other markets will act upon the supply and demand on the market for $X$. Those backward effects arise from the changes happening on all other markets that have been put out of equilibrium due to the initial variation of the price on the $X$ market. It is well known that Hicks mathematical analysis of stability would be discarded in the 1940s (Samuelson, 1941 and 1944) though some authors would tend to validate Hicks' intuitions regarding the role of substitutability, once properly recast as a set of differential equations 
(Metzler, 1944). The fact is that the perfect / imperfect stability typology is inadequate in modern studies on stability that would develop after WWII (Lenfant, 2018). ${ }^{20}$

As far as expectations are concerned, we may discard those weaknesses to understand the logic of Hicks' argument. With the perfect / imperfect stability typology, Hicks thinks to have found a device that permits him to model the behaviour of an economic system through time. On the one side, some activities and decisions within the economy can be characterized as taking place and adapting themselves quickly to some moderate chocks (unanticipated excess supplies or demand on commodity markets). On the other side, a set of other activities, more embedded into individual plans involving forward trading and expectations, would be better described as shaping an imperfectly stable system, especially since some specific markets are bound to be unstable by themselves on some occasions. The watershed between those two ways of thinking will depend on how Hicks makes allowances for expectations in economic behaviours. Note that since Hicks will explicitly neglect forward trading in his model, most of the intertemporal dynamics will depend on money demand behaviour (especially regarding the perspective of future trading needs).

In the first edition of Value and Capital, Hicks insists on the role of substitutability relations as a favourable property of stability, and argues that any system will actually be either perfectly or imperfectly stable, either in an exchange or a production economy. To sum up, Hicks ends with the idea that most economic systems are stable and that asymmetric income effects will generally be cancelled out by a "moderate degree of substitutability in the system" (VC, 72). In a general equilibrium model with production, destabilizing factors are even fewer. ${ }^{21}$ The general equilibrium of production is of wider applicability than the general equilibrium of exchange. Some practical problems, but not all of them, can be analysed with it (distribution in long period, international trade). Nevertheless, its principal limitation is that "it abstracts from capital and interest, saving and investment" $(\mathrm{VC}, 100)$ and "speculation": "This is a vital defect which we must try to remedy in the later part of this book." (VC, 100). All those items, that appeared already in Hicks' earlier works, will call for the use of expectations.

\subsection{From statics to dynamics}

What is of particular interest to us now is to consider how far Hicks himself regards this theory of exchange and production as a theory of the economic system, and how useful it will be for dealing with more complex issues arising with capital and money. I will insist on those passages in part II of Value and Capital where Hicks focuses on the relationships between the analysis of exchange and production in statics on the one hand and the analysis of capital and the dynamic process on the other hand.

Keeping in mind that the challenge of Value and Capital is to merge the study of a capitalist process and the theory of choice, we have probably the most important point here. From the outset, Hicks underlines two impediments to the use of the theory of choice to deal with capital and money, due to the assumption of the independence of prices on individuals' preferences or beliefs, which fails when a price change can indirectly retroact into another price change through expectations.

The first impediment is about the possibility of using the general equilibrium analysis when demand is linked indirectly with preferences, as is the case for the demand of inputs from the producer which depends on the price of the output (hence on his expectations about future prices). The second impediment is about the possibility of a speculative demand, especially in

\footnotetext{
${ }^{20}$ Developing more on Hicks and stability would lead us to unnecessary digressions through the history of global and local stability of the general equilibrium model of an exchange economy (see Lenfant, 2018)

${ }^{21}$ In a few words, the relations of substitution on the side of production are strong, and the production economy is less likely to be unstable and, if ever, "the danger of instability is concentrated on the factor markets" (Hicks, $1939,104)$
} 
the case of demand for money, which is "affected by expectations of the future" (VC, 57). Hicks postpones to part IV the proper examination of this case, thus pointing to the critical role of expectations:

\begin{abstract}
A fall in price may fail to increase demand, or may even diminish it, because it creates an expectation of the price falling farther. Here the marginal rate of substitution of the commodity for money ceases to be independent of prices because of a reaction through expectations. We shall see later (in Part IV) how important reactions through expectations may be" (VC, 56)
\end{abstract}

Here again, speculation, which is dependent upon expectations, is presented as a missing dimension in the static part of the theory, which makes it partly useless for the full understanding of the dynamics of a capitalist economy. At least, the theory of production can be studied with the principles of stability of an exchange economy. A standard commodity is taken as the standard of value and assumed desirable. Hence, it has only some qualities of money.

Whatever Hicks's warnings on the defects of the static theory of value, his main credo all along Value and Capital (especially in books III and IV) is to exhibit ways to simplify the theory of capital, interest, money, production and intertemporal choice to make the static framework of analysis adapted to them. To put it another way, the construction of the temporary equilibrium device has to find its place as a useful construction, which is not doing violence to actual behaviours and which can serve as a founding stone for dynamic analysis.

Hicks does not say clearly what of the present analysis will still be valid in a true monetary economy. Anyway, only the imperfect stability case is of theoretical interest, in the perspective of the analysis of a complete general equilibrium with capital and money.

Later on in this book I hope to show that there are some problems where imperfect stability is an interesting and important hypothesis. (Some of the most remarkable of them arise in connexion with the famous 'instability of credit'). (VC, 67)

Also, we are told that the pure model of exchange, abstract as it may seem, will be useful in part IV where dynamics is introduced in the system, because "almost exactly the same questions" will appear, and once adequately formulated, it "will turn out that we know the answers already. That is why the theory of exchange is an essential part of the study of the economic system in general" (VC, 77).

So far, it turns out that the fundamental dividing line between the tools of static analysis and the tools of dynamic does not consist in a list of missing concepts. It stems more fundamentally from the fact that it has been built upon a system of static expectations, where expectations are given and cannot change, in turn justifying the hypothesis of fixed preferences and beliefs and keeping them apart from the domain of prices. A burning issue is thus to understand how Hicks will be able to tackle the issue of expectations when he introduces dynamic into his model. This is precisely the task of part III to discuss both the method of the temporary equilibrium and the problems that arise when new kinds of transactions (forward transaction) and ways to hold wealth (money holdings) enter the stage.

In presenting part III of Value and Capital, I must limit myself to the presentation of those analytical tools that help to enhance the unity of method of general equilibrium and the role of expectations in economic dynamics. Dynamics begins where dating is important, so that a theory of capital, interest and money becomes necessary. Static analysis can be useful in the end if properly and "drastic[ally]" reinterpreted (VC, 116).

\title{
3.4 Temporary equilibrium and elasticity of expectations
}


Hicks's strategy for that is to provide an interpretation of the economic system so that each period can be isolated from past and future periods.

\begin{abstract}
Now we should be able to apply static analysis with the maximum of convenience if, when it comes to dating, we could date all these things to the same moment; if we could say that the system of prices existing at any moment depends upon the preferences and resources existing at that moment and upon nothing else. This is clearly not true (at least, not in the sense needed); but is there not some way by which it could be made to be true? (VC, 116)
\end{abstract}

The task of the temporary equilibrium device, precisely, is to make possible to use the static analysis at some points within a dynamic (non-stationary) representation of the economy.

Hicks introduces the notion of temporary equilibrium as a means to isolate some equilibrating processes from the dynamics of the economic system, thus also from an infinite regress of expectations and prices. To that aim, Hicks endorses the Marshallian vision of a sequence of periods characterized by different prices, expectations and plans. At the same time, he departs from Marshall, allowing for the interconnectedness of markets and providing his own classification, terminology and analysis of the process. ${ }^{22}$ The shortest period of time for trade between sellers and buyers is called a Week, that period of time during which an equilibrium of prices will be reached (on the Monday) and spot contracts will be carried out (the Monday and the Rest of the Week. The process of equilibration of markets on Mondays is swift and homogeneous (applies to all market participants), so that variations in prices during the Monday are negligible (they do not distort the distribution of wealth, and the final equilibrium is almost the same as the theoretical-Walrasian-equilibrium). Through time, weeks after weeks, prices will change discontinuously. This purely dynamical process has to be dealt with separately, and we can presume that it will take as data the discontinuous series of prices obtained through successive temporary equilibria.

Let us describe more in greater details the Temporary Equilibrium device (Chapter X, Equilibrium and Disequilibrium). Every Monday, markets open with a set of prices that can differ slightly from the closing prices of the preceding Week. Those prices are presented as "guesses" on the part of traders that intend to participate in the market. They are manifestly influenced by expectations forged during the previous Week as to what would be the state of supplies and demands on the Monday morning. On the opening of the Monday, "the whole material equipment of the community,..., including the finished goods now ready for sale, the half-finished goods and raw materials, the fixed plant of all sorts and the durable consumers' goods, must be taken as given." (VC, 131). As in a short period situation, it is still possible to produce more or less according to the state of supply and demand on each market, so that the total amount of each commodity or of labour is not strictly fixed. On the basis of the opening set of prices, traders contract and realize that some markets are in excess supply and others in excess demand. This is the starting point of a double process:

i) Of revision of prices, under the laws of stability of the static general equilibrium method;

ii) Of revision of expectations about future prices. For the sake of simplicity, Hicks assumes that expectations are determinate, that is, there is no uncertainty and risk component.

During this process of determination of equilibrating prices on Mondays, it is likely that some agents will change their expectations about the equilibrating prices, but those very short term changes are assumed away as negligible, that is, their swift stabilization is a guarantee that income effects will be insignificant on the final price equilibrium reached by the end of the

${ }^{22}$ We shall not discuss in detail the similarities and differences between the Marshallian period analysis and Hicks temporary equilibrium; nor shall we enter into a critical assessment of Hicks' device (De Vroey, 2006). We think, however, that the analysis of the temporary equilibrium device would benefit from a parallel consideration of Hicks' views about expectations and their role in the economic process. 
Monday. This process is supposed not to alter significantly the revision of prices during the current Monday (and eek). However, nothing guaranties that the system of plans adopted by the end of the Monday is in accordance with the new system of expectations about future values at that date. Nevertheless, Hicks imposes some stabilization of expectations for the rest of the Week and implicitly considers that the backward effect of expectations on current plans during the equilibrating process of prices does not modify the equilibrating price and does not jeopardize its stability. During the rest of the Week, traders will carry out contracts signed during the Monday. At the end of the Monday, prices have reached an equilibrium-a temporary equilibrium of prices.

In the next Monday, a new Week is starting with a system of prices slightly different from the temporary equilibrium of the preceding Week and with (most likely) diverging plans between sellers and buyers on each market. It is the starting point for a new process of equilibration, according to the laws of perfect stability. The dynamics of the system will thus correspond to the process of change "consisting of a series of temporary equilibria." (VC, 127), each representing an equilibrium to which a set of plans and expectations are attached (preserving the logic of choice).

Thus, expectations here are designed as the set of beliefs about future prices, given at the opening of a Monday, that affect current prices during the Monday until an equilibrium is reached. It is essentially through the alteration of plans that current prices reach an equilibrium (an equality of current demand and supply) (VC, 131-132). For all that, it is in the nature of a temporary equilibrium dynamic that agents' expectations about prices are cheated at all periods (VC, 133) and this is a sufficient cause of inefficiency, which can be more or less important.

This needs further comments. We need to understand how far Hicks allows for expectation revisions within the Week. The one important and relevant cause of disequilibrium is when agents tend to have the same price expectations and incompatible plans, which will induce price adjustments -within the Monday and accordingly new plans and price-expectations. In this case, the revision of expectations is innocuous on final prices, bearing only on future prices. The other cause of disequilibrium is related to a discussion about the effect of risk on agents' plans. An increase in risk perceived about the chances of various situations will reduce confidence in the realization of an average situation and push entrepreneurs to produce less than they would have otherwise, clearly a situation of ex post validation of ex ante (individual) expectations. "In this way the efficiency of the system may be seriously damaged, without any of the types of disequilibrium mentioned above coming into question. This is a possible source of waste; but of course lack of confidence in one's foresight is not necessarily a source of waste. The loss only accrues if expectations would have been right after all." (VC, 134). ${ }^{23}$ However, Hicks will put this cause of disequilibrium outside of the temporary equilibrium device, avoiding any complex spillover effect of expectations. To Hicks, the Temporary Equilibrium device is mostly adapted to think of situations when the short term adaptation of plans and prices leads swiftly to temporary equilibrating prices. During this process, expectations are partly adapted in a way that makes the current equilibrating prices only temporary. The temporary equilibrium is the counterpart of future maladjustments of plans in future weeks. It is still possible that some expectations might evolve during the rest of the Week.

Avoidance of the element of risk at this stage is enshrined in the Temporary Equilibrium device through the restriction of transactions to spot transactions, excluding any forward contract. Thus Hicks is avoiding any maladjustment for future plans and future prices to retroact on current prices. This is a most unrealistic justified by the needs of the model. "Owing to the limitations of forward trading, this model is not really a very drastic simplification of reality."

\footnotetext{
${ }^{23}$ Note that on this issue of the possible causes of disequilibrium Hicks $(1939,135)$ discusses the advantages of a Socialist organization over a Capitalist one, mentioning that the correct price expectation / incorrect plans is typical of a Capitalist organization.
} 
(VC, 140). A next step is then to show how such concepts as interest and money can be cast adequately in the framework of a Spot economy. As far as interest and money are concerned (Chapter XI and XII), Hicks upholds that one could indifferently conceive of an economic system in which the interest rate is a long term rate (as most economists do) or an economic system in which each long term loan takes the form of a repeated one week contract, even though "that is a much drastic abstraction" (VC, 148). The only difference stands in the kind of expectations one puts to the fore. The former is more in tune with the wants of industrial borrowing while the latter is more agreeable to lenders. In either case, the idea of forward trading can be discarded. ${ }^{24}$ The same way, it is a matter of convenience if one wants to deal with a monetary theory of the interest rate rather than with a loan market approach.

The temporary equilibrium device reflects behaviours made on the basis of ex ante values. ${ }^{25}$ The concept of income, saving and investment are ill-defined in a non-stationary economy, and should be avoided in a study based on choice rationality: "In order to get clear-cut results in economic theory, we must work with concepts which are directly dependent on the individual's scale of preference, not on any vaguer properties of his psychology" (VC, 177)

\subsection{Elasticity of expectations and the functioning of the adjustment process}

Expectations in Value and Capital are remembered above all because Hicks has introduced the notion of elasticity of expectations as a means to study the dynamics of a general equilibrium system. It is conceived of as a generic notion that can be adapted to describe the effect of the system of expectations in bridging the periods, in studying the sequence of temporary equilibria through time. Actually, the tool can be used with a view of introducing already some dynamic changes within the temporary equilibrium process. This is discussed in detail in the fourth part of the book: "The Working of the Dynamic System".

Producers and consumers' decisions are now affected not only by current prices but also by interest rates, price expectations and interest rate expectations, and decisions concern commodities, securities and money. Producers have to make a production plan on the basis of the current prices and their expectations about future prices. They will strive to maximise the capitalized value of the stream of surpluses (receipts-costs). ${ }^{26}$ This behaviour is studied under various assumptions about expectations, and provides us with the laws of the working of the price system within a Week, "and that is only the beginning of what we should like a dynamic theory to tell us" (VC, 191). Such a statement blurs the frontiers of dynamic by introducing expectations and capital decisions into the Week. We have to consider how far Hicks goes in this direction.

Thus, to examine the entrepreneur's plan, it is necessary to make allowance to price expectations and interest rates expectations. The study of dynamic and the analysis of the effects

\footnotetext{
24 "The particular problem left for us to discuss here is the determination of the system of spot prices established on a particular Monday; and it divides into two sub-problems, according as we assume short lending, or long lending, to be the only kind of lending practiced" (Hicks, 1939, 154)

25 "Ex post calculations ... are of no use to theoretical economists, who are trying to find how the economic system works, because they have no significance for conduct" (Hicks, 1939, 179). Even if a Temporary equilibrium contains partly some adaptation of expectations, most of the adaptation of expectations is charged on future weeks plans, and makes for the temporary equilibrium to be an ex post equilibrium with windfall gains and losses. It makes sense to say that those windfall gains and losses take their part in the revision of expectations and plans from one week to the other. The ex post / ex ante distinction is taken from Myrdal's Monetary Equilibrium, which had been translated from Swedish to German in 1933.

${ }^{26}$ It leads to intertemporal maximization conditions: the marginal rate of substitution between inputs of any two dates must equal the ratio of their discounted prices, and the marginal rate of transformation of any input into any output must equal the ratio of their discounted prices. Another dynamic condition is that at each date the capitalized value of the output must be positive. Usual stability conditions also apply.
} 
of price expectations and elasticity of price expectations is done sequentially, following Hicks' methodological credo, which consists in establishing step by step the necessary amendments to the results of static theory to account for new economic disturbing causes in the agent's behaviour. Notably, the first step consists in focusing solely on the effects of prices changes and changes of price expectations on the production plan, leaving out for a next step the "formidable complication" (VC, 202) of allowing for changes in interest rates and interest rates expectations.

Hicks first discusses the hypothetical effect on the production plan on Monday (including its behaviour on Monday) of changes in prices and changes in price expectations (chap. XVI). This is an analysis of the various static laws of the firm's plan. The discussion will be structured around a combination of different elements affecting the production plan (the consumer's plan is regarded as relatively less sensitive in this respect):

i) The changes in entrepreneurs' expectations.

ii) The various effects of a price rise and a price fall and the effects of an output price variation and an input price variation (it does not change the ratio of discounted values)

iii) The various situations of (intertemporal) technological complementarity and substitutability.

Taken together, those elements open up to a wealth of possible cases. The most important item, however, is that of expectations, if the theory of the production plan "is to lead to useful results" (VC, 204). Changes in expectations are a fundamental element in the understanding of the dynamic of the temporary equilibrium. They are discussed through a technical measurable device, viz. elasticities of expectations. Elasticity of expectations are a necessary means to make the static theory adaptable to situations when a variation in the current price of an output or an input is not interpreted as a temporary rise.

\footnotetext{
"We may classify cases according to the elasticity of expectations. I define the elasticity of a particular person's expectations of the price of commodity $\mathrm{X}$ as the ratio of the proportional rise in expected future prices of $X$ to the proportional rise in its current price. Thus if given expectations are rigidly inelastic (elasticity 0 ) we get the case of given expectations. If the elasticity of expectations is unity a change in current prices will change expected prices in the same direction and in the same proportion; if prices were previously expected to be constant at the old level, they are now expected to be constant at the new level; changes in price are expected to be permanent. Obviously these two are the pivotal cases. But it is also useful to be able to distinguish the intermediate case of an elasticity of expectations less than 1 and greater than 0 ; and the two extreme cases, of an elasticity greater than 1 and a negative elasticity." (VC, 205)
}

The last two extreme cases correspond to situations where people "recognize a trend" and extrapolate it. In the case of a negative elasticity, they feel that the current change corresponds to the culmination of a trend and they anticipate the fluctuation (VC, 205)

Elasticity of expectations are essential for understanding intertemporal substitutions within agent's plans of production or consumption, and will thus prove fundamental for the understanding of the dynamic of temporary equilibria. Notably, the unit elasticity of substitution is a limit case with no "opportunity for substitution over time" (VC, 206):

In the case of a zero elasticity of expectation (the price increase of good $X$ is seen as temporary), there is a short-term substitution in order to produce more of $X$ and of complementary outputs, through either diminution of other outputs or increase of inputs in the current period, etc. In the case of an elasticity of expectations equal to unity (permanent increase), there should be a rise in output without substitution between periods, except that the rise in production will necessarily be gradual, due to technological obstacles in the short run. 
The next step in the analysis of the dynamics of the entrepreneur's plan is to introduce expectations about interest rates within the picture. It is beyond our purpose to discuss in detail the arguments brought about by Hicks on this "really controversial question" (VC, 213), culminating in an attempt at revitalizing the average period of production theory of BöhmBawerk against Knight' criticism. (This is done mainly through a present value of a stream of expected surpluses approach). The main points to be retained, as far as expectations are concerned, can be summarized as follows.

In the pivotal case of a unitary elasticity of expectations in interest rate - a change in interest rates is expected to be permanent - there is a proportionate change in the discount ratio per week for loans of all durations, with the consequence that the changes within the discounted prices (the ones relevant for the plan) are not proportional: "discounted prices of the outputs and inputs further ahead in time are regularly affected more than the discounted prices of the nearer outputs and inputs." (VC, 214) The theory leads to assume that in most cases, an expectation of a decrease in the interest rate will induce a crescendo of the production plan (favouring the increase in output in the more distant future more than in the near future), even though distribution over time depends upon technical conditions. The most important lesson of this investigation concerns its practical use and the time horizon of the entrepreneur. To Hicks, the usual span of variations in the interest rate (between 2 per cent. and 7 per cent.) is too small for it to be influential upon the entrepreneur's plan (except in "special cases"). By contrast, a slight variation of the expected rate of interest far forward is likely to exert a strong influence (through the discounted price effect). Hence, the actual effect of the interest rate on the dynamic of an economy is likely to depend (among other things) on the condition that determine the planning horizon of the entrepreneurs, hence on the importance they give to their own expectations. Those conditions are both technical and related to the risk environment.

Before to arrive at the climax of Hicks's analysis of the dynamic of the economic system, we still have to set out the planning behaviour of households, not as regards goods, but as regards intertemporal consumption, through spending and lending (hence also through money demand). We will be content here with summarizing. Even if they do not anticipate in detail the flow of expenses they will make, they nevertheless conceive of an accurate plan of the flow of surpluses they would like to manage within a finite time horizon.

Once the problem can be formulated as only an intertemporal choice problem-relative prices within each period being fixed - the static theory applies easily, with due consideration for substitution and income effects.

In the case of an elasticity of substitution greater than unity:

\begin{abstract}
"The substitution against buying $X$ now, which follows from the rise in the current price, may then be overmatched by the substitution in favour of present purchase, induced by the greater rise in expected prices. If the elasticity of expectations is large enough, the income effect too may be outweighed; and the final result may be that current demand is increased. This is the familiar case of speculative demand." (VC, 232)
\end{abstract}

As to the effect of the rise in the interest rate on borrowers and lenders, the substitution effect causes a general substitution of future expenditure for current expenditure. And Hicks considers that borrowers being quicker to adapt their behaviour than lenders, the net income effect will be in the same direction as the substitution effect and will reinforce "the conclusion that, for the market as a whole, a rise in the rate of interest will reduce current expenditure, a fall in the rate of interest increase it" (VC, 235). ${ }^{27}$

\footnotetext{
${ }^{27}$ Once money holdings (and not only security holdings) are accounted for, Hicks repeats the main reasons for holding money (Hicks, 1935a) in a context of transaction costs, risk and uncertainty, making demand for money sensitive to risk, interest rate, planned increase in security holding in the future. Also, precautionary holding of
} 


\section{Expectations and the Laws of Dynamic}

Once a presentation of behavioural laws of producers and consumers has been discussed, Hicks comes then to the general discussion of the dynamics of the whole system, accounting for aggregated effects of behaviours on various markets (goods, securities, money) and for the sequential effects on plans on the supply and demand side of variations of current prices and interest rates. The whole set of chapters is divided into two parts, one discussing the short term 'dynamics' within the temporary equilibrium device while the last two chapters tackle the true dynamics, that is the series of temporary equilibria as capital accumulation takes place.

\subsection{Dynamic within Temporary Equilibrium}

Here we arrive at the three most important chapters dealing with the temporary equilibrium of the whole system. ${ }^{28}$ Applying the method of stability analysis makes it possible to deal "with scarcely any transition, from the little problems involved in detailed study of the behaviour of a single firm, or single individual, to the great issues of the prosperity or adversity, even life or death, of a whole economic system" (245, our emphasis)

We feel that it will be worth its while, however, to discuss what is behind the "scarcely any transition" alluded to by Hicks. Chapters XX to XXII are devoted to presenting the temporary equilibrium when all aspects of agents' decision are taken into account, but capital accumulation has not yet exerted its own effects on the productive structure of the economy. The logic behind those chapters deserves some comments. Chapter XX, with a subtitle "Its Imperfect stability", sets the stage about what kind of phenomena ought to be captured through this device, and how far they represent a part of the modelling of the dynamic process. It is of utmost importance to understand what is this part made of, and how expectations play their own part into it. Through his analysis, Hicks aims at showing that the temporary equilibrium of an economic system is inherently imperfectly stable, and that it can even prove unstable in some plausible circumstances when elasticities of expectations are unitary or greater. It is then the aim of chapter XXI to identify "Possible Stabilizers" of such an economy, through a discussion about agents' reactions towards variations in the rate of interest, agents' interpretation of prices and price rigidities. This chapter, undoubtedly, deepens Hicks views on expectations. At last, chapter XXII proposes to put some order into the wealth of behavioural possibilities offered by the theory and to select those that are most likely to operate.

Chapter XX is certainly destabilizing the reader's views about the logic behind the temporary equilibrium. In this chapter, Hicks shows some flexibility and hesitations about the adequate balance of explanatory power between what is taking place within the boundaries of the temporary equilibrium device and what is to be left to be explained through the dynamic of the system, that is through the series of temporary equilibria. Clearly, there is an important choice here, which cannot be simply discarded by arguing that the temporary equilibrium is not concerned with the effects of capital accumulation (a Marshallian short term period analysis) while the dynamic would address specifically these effects. Actually, there are two stakes behind the choice of a separation.

\footnotetext{
money increases when an increase in expenditure (for consumption or production) is planned in the near future (a view emphasised by Keynes (1937)).

${ }^{28}$ Hicks claims that his method of analysis leads to consider that the behaviour of a whole group of producers or consumers was the same as the behaviour of a single unit and that all what matters is captured by "income effects" that can be different from one group to another (Hicks, 1939, 245). Thus, the analysis is not strictly based on microeconomic foundations, in the sense that Hicks points to the importance of considering group behaviours, each characterized with specific properties relevant to the understanding of the dynamic process. At the same time, it departs clearly from a representative agent approach, and heterogeneity remains, though in the background, a relevant feature of Hick's approach.
} 
Firstly, the more the temporary equilibrium device is associated with a long term environment, the more it is brought into complex temporal mechanisms (as against a pure market period), that reduce the validity of the principles of stability analysis, especially the perfect stability / imperfect stability device of a production economy. The consequences are that Hicks introduces the idea of a third possibility, that of instability. The only mathematical interpretation is that even when all markets have been retroacting on an initial discrepancy in the market for $X$, the latter is not brought back to equilibrium. Even if Hicks would like to provide some rationale for thinking about this state of affairs as limited within boundaries, he does not discuss the exact analytical meaning of instability, and one would need further interpretation of agent's behaviour when they face such a system.

Secondly - as a follow-up of the previous remark and in accordance with Hicks' methodological views - the proper balance of boundaries should be legitimated in relation with behavioural assumptions, that is statements about how agents' perceive their environment, rather than objective knowledge of this environment. This split cannot be fully satisfactory as long as Hicks has not given good reasons to distinguish between the behavioural logic of the temporary equilibrium and the behavioural logic of the dynamic process.

No doubt, there is a Gordian knot here, and we have to see how Hicks breaks it and what are the consequences on our understanding of expectations.

Hicks warns us that the logic of analysis of the temporary equilibrium leads to consider comparative static issues (say, a change in resources or a change in expectations) with a view of comparing the set of equilibrating prices obtained in both situations. The result, as he says, "is not the ultimate dynamic problem" and "we are even yet not in a position to give an account of the process of price-change, nor to examine the ulterior consequences of changes in data" (VC, 246). Hence, Hicks has to explain what it is that we know once we have dealt with the 'working' of the economy over the week. Here, I think, there is a time dimension entering the logic of explanation. The comparative statics of the temporary equilibrium delivers information about the "immediate alteration" that will affect the "course of events" following a change in data. The meaning of "immediate" is variable, since the length of the week is arbitrary, and the upper limit is that of capital accumulation or decumulation, which "belong to a part of dynamics which falls outside temporary equilibrium theory" (VC, 247). Those boundaries must be associated with changes in the agents' perception, however. What counts, then, is "time necessary for entrepreneurs (and others) to wake up and change their plans". Here we have a central feature of the reasoning: The duration of the week is aligned on this time for changing plans, and at the same time the effects due to the relative slowness or swiftness with which various agents become aware is neglected.

Hicks is conscious that there may be some weaknesses with this method. Firstly, if capital accumulation can proceed quicker than agents' awareness of simple disequilibrium, there may be some overlap of processes. It is however asserted that "it is rather useful to be able to distinguish, on the one hand, those consequences of the initial change which result simply from people's awareness of the initial effects..., and, on the other, those effects which depend on capital accumulation, and whose dating is thus more or less strictly determined by the technically given duration of the processes needed to bring about changes in productive equipment" (VC, 247). We would then be tempted to say that Hicks dissociates a time for agents' subjective accounts and catallaxy from a time for technical constraints. There is thus a difference in the nature of the processes taking place, which ultimately accounts for the boundaries of the temporary equilibrium. On this occasion, two kinds of laws operate: the agents' laws of behaviour are likely to operate "with the maximum of rapidity" and to be monitored "considerably"; while technical constraints are not flexible in time.

Hence, we should conclude that there is a distinction between expectations that play their part within the temporary equilibrium time duration and those that may eventually complete 
them once new information about capital accumulation are taken into account. The former are assumed to be swift, independent of structural laws of capital accumulation, and sensitive to some kind of policy intervention.

\title{
4.2 Searching for a demarcation between dynamics within Temporary Equilibria and dynamics between Temporary Equilibria.
}

The source of imperfect stability can originate in the new behaviours that characterize the temporary equilibrium device, that is, spending and lending behaviours, or equivalently, decisions about net holding of securities. As soon as the elasticity of expectations are no more zero, expectations have a backward effect on prices, and potentially a destabilizing effect, the critical case being when a unitary elasticity of expectation prevents substitution over time. The full consequences of this situation are experienced in a true monetary economy (with a genuine money bearing no interest). A rise in the price of a commodity, interpreted as a general permanent rise of all prices, leads to an unending process of price rise (with no determinate level of money prices). This breakdown situation is "a quite plausible simplification of reality", and at the same time it is not something adapted as a modelling device, because of this very disruptive property. As we have seen, Hicks conception of the economic world is not made of disruption, it is a world of substitution, of smooth evolutions, and models to represent them have to allow for a gamut of temporal processes. To extract oneself from the comfort of the stationary state leads to account for instability due to expectations and for possible stabilizers. ${ }^{29}$

At the same time, Hicks seems to make good use of the instability case, because it can make sense of some features of economic systems that cannot be represented through the perfect stability / imperfect stability device erected for the static system. Hence, expectations (elasticities of expectations) open to a broadening of the toolbox of the economist to model fluctuations, conditionally on their ability to identify counteracting behaviours that transform an unstable, potentially chaotic situation into a fluctuating (cyclical) phenomenon. Thus, we can expect from chapter XXI ("Possible Stabilizers") to deliver some clues as to the role of expectations. At the same time, it seems that cyclical movements are now becoming part of the temporary equilibrium device. An intriguing fact, indeed.

\begin{abstract}
"We are now in the position of having constructed a model economy, which we have found to lie upon the verge of instability. It is not a realistic model; it is a very much simplified model; yet it appears to have some relevance to actual situation. The kind of instability it exhibits is recognizable as being akin to the instability we seem to detect in the economic systems of reality - the instability which makes them liable to fluctuations; nevertheless, though they show this instability, they do not seem to be unstable to such an exaggerated degree. Consequently, somewhere among the modifications which would have to be introduced if our model is to be made more realistic, we should expect to find possible stabilizers-elements which limit the fluctuations of the economy, though they do not prevent it from fluctuating altogether" (VC, 258)
\end{abstract}

A pending question is whether these fluctuations are thought of as taking place within the temporary equilibrium time span, and what will be the role of expectations in this process.

The most important stabilizer is the rate of interest, the only price whose movement had been frozen in the discussion of the price movement in chapter XX. So, it is a test for stability. A change in prices (and expected prices) will necessarily bear upon the planned expenditure of

\footnotetext{
${ }^{29}$ Note that to Hicks, his model shows that instability is caused by the fact that the economy is a monetary economy (with money and securities), and not specifically by the fact that money wages are variable, an artifact of Keynes' reasoning in the General Theory (see Hicks, 1939, 256-257)
} 
agents, hence on their demand for money. The reaction through interest rate (if the supply of money is not changed), would lead to a subsequent check in the price change. Though this situation is likely to occur in the case of a price increase, it is much less certain in the case of a price decrease (the liquidity trap), when the initial value of the interest rate is so low as to prevent its further lowering. A general explanation of Keynes' theory needs to take account of expectations about interest rates. For the first time, Hicks discusses expectations on interest rates. If expectations were inelastic, the shift in the interest rate made necessary to check a fall in prices (and the consequential decrease in money demand, in the face of a constant supply) could necessitate a negative interest rate. On the contrary, in the case of elastic expectations, the fall of the interest rate is (immediately) interpreted as permanent; hence it triggers an additional demand for goods (due to the increase in the discounted prices of goods in the future). The excess supply of money is diminished and equilibrium on the money market can be obtained through a smaller decrease in the interest rate.

Here we touch at some important remarks regarding the properties of expectations about interest rates. To Hicks, elasticities of expectations on the price of commodities are different from elasticities as regards interest rates, whose stabilizing influence will depend upon its relative sensitivity to price expectations. Hicks is not very optimistic on this account. "Unfortunately it does not seem likely that highly elastic interest-expectations are as common as highly elastic price-expectations." (VC, 262) Here at least Hicks points to a differentiated view on the formation of expectations. Ups and down in the price level can be associated with sort of a normal-prices situation by agents (sort of an original notion of equilibrium called "quiet times"). While the same agents are fundamentally sensitive to interest rates, small variations in interest rates may be compatible with quiet times, but no more as soon as some "broad limits" have been reached. Interest rates engage people through time and thus through risk; and risk cannot be steadily sustained in high limits. Because agents believe that risk must be set to a normal value in the long run, they tend to interpret a deviation of the interest rate from its normal level as a purely temporary move. Thus there are reasons for the expectations of interest not to be very elastic (VC, 262). To put it differently, Hicks makes us understand that interestexpectations obey a different temporal process than price-expectations, they do exhibit a stronger inertia, since it takes more time for agents to take a variation in the interest rate as a permanent change (or as changing the normal reference value of the interest rate) (VC, 262n2). This is certainly of utmost importance if one wants to draw a demarcation between Temporary Equilibrium and true dynamic.

\subsection{Heterogeneity and expectations}

We cannot hope too much that interest expectations are likely to work efficiently as a stabilizer, a situation that is comforted also by the fact that a change in the long rate, even if obtained after some inertia, is only likely to exert an influence on prices if it exerts an influence on the production plan of the firm, a situation which is scarcely possible under depressive conditions. Everything happens as if the risk component over the long term valuations is offsetting the possibility of a recovery.

Translated in terms of expectations, we would have to say that (even) expectations about long term interest rates are ineffective on the system, due to counteracting expectations of a price decrease. This deficiency is a feature of depressive economies, and does not work symmetrically in the case of a price increase; it makes monetary policy probably inefficient to monitor a fall in the interest rate. In the case of a price decrease, the burden put on debtors increases, and with it the risk of bankruptcy and payments defaults, a situation which is shortly interpreted by lenders as an increased risk, with chain reactions inducing agents to hold more liquid assets. This is a case of "depression psychology", during which a higher interest rate does 
not compensate for the increased perceived risk of systemic failure (Hicks does not use that wording). This climate leads to sustained deflation.

All those processes are assumed to take place within the temporary equilibrium framework, so that clearly Hicks blurs the boundaries.

A way out of the depressive psychology comes from price rigidities. Some prices are rigid, hence relative prices are not constant throughout. To Hicks, It is not realistic to assume that agents have unitary expectations about prices and at the same time rigid expectations about wages.

\footnotetext{
"The rigidity of wages extends over precisely that time - it may be quite a long timeduring which the parties concerned persuade themselves that changes in related prices $\ldots$ are temporary changes. Once they become convinced that these changes are permanent changes, there $i$ s a tendency for wages to change; in situations of extreme instability, when they have lost their sense of normal prices, negotiators have recourse to automatic sliding scales and the rigidity of money wages ceases altogether" (VC, 270)
}

Thus Hicks rejects Keynes' stabilizing factors as unrealistic. We have here perhaps one of the first instance of a statement about the formation of expectations as being partly a collective process through wage-bargaining. The notion of "normal prices" thus becomes a collective notion in a capitalist economy, and it calls for an explanation of wage rigidities through inelastic expectations. I think that we find here another instance of the idea of thresholds and heterogeneity in people's formation of expectations.

\footnotetext{
"There must be a tendency to rigidity of certain prices, particularly wage-rates; but there must also be a tendency to rigidity of certain price-expectations as well, in order to provide an explanation for the rigidity of these prices. There is no reason to suppose that all price-expectations are inelastic. Indeed, we should do better to assume a good deal of variation in different people's elasticities of expectations. Some people's expectations do usually seem to be in fact fairly steady; they do not easily lose confidence in the maintenance of a steady level in the prices with which they are concerned; so that, when these prices vary, their natural interpretation of the situation is that the current price has become abnormally low, or abnormally high. But there are other people whose expectations are much more sensitive, who easily persuade themselves that any change in prices which they experience is a permanent change, or even that prices will go on changing in the same direction." (VC, 271)
}

Differences in the sensibility of expectations reflect themselves according to the kind of goods traded. "The most sensitive prices are found in those markets which are marked out in common parlance as 'speculative markets"” (VC, 271)

Far from searching a universal principle of explanation for expectations, based on a unique set of information, stresses instead that people's expectations are linked with their personal history, and that this must be part of any explanation about economic dynamics. Incidentally, one may infer from this the importance of historical events and collective memory, and the importance of economic history to Hicks. When Hicks introduces considerations about the heterogeneity of expectations elasticities in the population, it seems to be linked with history and generational values. "People who have been accustomed to steady prices, or to very gradual price-movements, are likely to be insensitive in their expectations; people who have been accustomed to violent change will be sensitive." (VC, 272) Apart from a generational difference (which in itself creates heterogeneity of sensitivity within a population) difference in sensitivity may arise also from various individual experiences due to specific occupations and representations of the economic system. The extremes of these collective features are a "settled" community and a "neurotic" community. It is interesting to note that to Hicks, the aggregate 
level is the one important level, not specifically the individual one, even though his wording is sometimes ambiguous (psychological condition of the individuals play their part too) (VC, 272).

On this occasion, it turns out also that the temporality of the Temporary Equilibrium becomes loose, because sensitivity depends on the length of time considered in the analysis. The week is arbitrary in length, and

\begin{abstract}
"the elasticity of expectations depends upon the relative weight which is given to experience of the past and experience of the present; now if the 'present' is taken to cover a longer period of time, 'present experience' will necessarily weigh more heavily, and (even in the same psychological condition) expectations will tend to become more elastic." (VC, 272)
\end{abstract}

Hence, Hicks sticks to the idea that people are attached to some idea of normal prices, built on past experiences, and will need sufficient cases of deviations from those normal prices to reconsider their beliefs. Hence, sensitivity, and elasticity of expectations, are to depend on the length of the week. Hicks does not seem to be afraid that the temporary equilibrium would become devoid of interest if the length of time is extended. To make sense of this, it is only important to keep in mind that outside the temporary equilibrium, there are some other phenomena not yet dealt with, which will affect the properties of the economy in the long run.

One would expect the third chapter devoted to temporary equilibrium to clarify the functioning and the understanding of the equilibrium price attained within the temporary equilibrium device. Actually, chapter XXIII on the "laws of the working of the temporary equilibrium" will develop the representation of it as a temporal process during which various first and secondary effects lead us to some laws about movements in prices and interest rate. It is presented as a summary of the Temporary equilibrium device, taking account first for autonomous changes on markets (either for goods, or money, or securities), then adding to it supplementary effects associated to positive elasticities of expectations, with a separate treatment of the effect of elasticities of price-expectations and elasticity of interestexpectations. Understandably, Hicks limits his investigation to a simplified economy in which agents deal with money, securities and goods, all being substitute to each others, ${ }^{30}$ income effects being assumed negligible. ${ }^{31}$ The initial gap in markets can easily be attributed to an incompatibility of plans from one Monday to another.

As a first step, it is assumed that markets react under inelastic expectations, then as a second step, through a change in expectations. Both the primary and secondary effects could be taken to take place simultaneously, but Hicks seems to consider as a side effect of his sequential reasoning that it illustrates reasonably well some temporal processes of causality. In other words, some price adjustments have to take place before agents take them into account in their plan, in turn changing their expectations about future prices or interest rates. Hicks never questions the very possibility of finding such an equilibrium through changing expectations and plans, not even its mere existence (Grandmont, 1977) ${ }^{32}$ Neither does he question the possibility that the process of price and expectations adjustment could generate strong income effects.

\footnotetext{
${ }^{30}$ Hicks assumes that money and securities are very close substitutes (a proof of it being the case of small interest rates in general). Hence, the relation of commodities to either securities or money cannot be but symmetrical, hence a relation of substitutability (since two relations of complementarity are excluded in a three goods economy.

31 This method is in conformity with many simplifications made in the static part of the book. Hicks follows the same principle of sequential reasoning, assuming that comparative statics results allows to think of the stability of the system.

${ }^{32}$ Note, however, that Arrow and Nerlove (1958) have established a stability theorem for a dynamic general equilibrium when prices are affected by expectations à la Hicks.
} 
Hence, the enrichment of the model through a temporal account of how expectations are likely to form themselves through experience of changing prices is at the cost of making the length of the temporary equilibrium excessively long, blurring the meaning of it as a representation of a quick adjustment mechanism.

The main question to be answered is whether, following a disequilibrium on the goods market (a rise in the demand for goods in terms of money), the equilibrating process will tend to adjust in a balanced way on the money market or on the securities market, and what will be the final effect on the rate of interest. With inelastic expectations, the adjustment would take place rather on the monetary market, and if ever, there would be a slight decrease of the interest rate. Now, when price expectations are allowed to modify the final equilibrium, the final effect is much less clear, and one cannot say if an expected rise in prices would be financed more by dishoarding or through borrowing. As elasticities of expectations on prices increase, "the rate of interest is likely to move in the same direction as the price-level" (VC, 279), hence it exhibits instability. "A world in which an increased demand for securities in terms of money may (even in the end) raise the rate of interest has its instability proclaimed aloud by this condition alone" (VC, 279)

Instability is certainly a feature which is dependent also on the proper length of the temporary equilibrium, as elasticities of expectations become more elastic as more time elapses. Here, we get additional views about the formation of expectations; Hicks shows, once more, how is Temporary Equilibrium device rests upon an unstable representation of the role of expectations through time.

First, people establish their expectations on the basis of a small sample of prices, the ones with which they are concerned directly. We can consider that they have various representations of the economy and an incomplete knowledge of the economic system. This may well influence the path of price increase (two apparently distant goods may show high reactivity because they are traded by sensitive persons).

Second, Hicks retains an idea of heterogeneity of sensitiveness among agents, which does not stem from purely psychological features, but to community features, some trading communities being more sensitive than others. Wage rigidity is a case of low elasticity of expectations. Interest rate expectations are bound to be weakly inelastic (or comparatively less than price elasticity of expectations), but their effect in changes on long term interest rates are more durable. Short rates are an adjustment variable much more sensitive except if it is already low. Elastic expectations of interest rate make it possible to reduce variations of the short run. However, Hicks thinks that in general, interest elasticity of expectations are weakly elastic and the long run rate is governed by expectations about policy monetary issues" (VC, 282)

Curiously, we are left with a picture of the temporary equilibrium, its ability to reach an equilibrium and to stabilize future expectations, which is unfinished. Hicks maintains some vagueness about the reasonable duration of such a process of expectations- and prices revisions, though he asserts that all those repercussions would "take place immediately, if people were sufficiently alert and if communications between markets were good enough" (VC, 283).

\subsection{Expectations and the trade cycle}

To those reactions which are ultimately constrained by institutions and psychology, Hicks opposes some others which are constrained by production technics and capital structure (sort of a Hicksian dichotomy). Plans that have been drawn during the Mondays unfold themselves. On each new Monday, plans are confronted. The new element in this confrontation is that the capital equipment available on one Monday morning is no more that of the previous Monday, due to increase or decrease in capital equipment (in various industries) during the previous week. The new problem which we face now is to deal with the effect of these evolutions on prices. Some producers have increased their supply of some goods, but at the same time are 
expecting higher receipts and might have planned to buy more. On the whole, the price-level could be maintained at an approximately constant level. If entrepreneurs do not spend the whole of their prospective increase in income, then there will be a movement downward of prices (when capital goods become ready). This is the kind of mechanism retained by Keynes. On the contrary, if the investment in new capital goods takes more time than a week, there will be no additional supply on the second Monday, while entrepreneurs will be likely to spend part of their anticipated receipts. ${ }^{33}$ If there is no increase in the production possibilities on the second Monday, there will be a tendency to raise prices. This will depend of course of the previous plans of production of capital goods in the past periods. There is no reason why the pattern of increments to the output would be matched with the increment in income within a nonstationary economy. Potential disturbance, then, will depend on individual's course of expenditure plans in the face of future expanded income, and in practice, it will depend also upon dividend policies of companies. Here we have the seeds of variations in prices. "The natural thing to expect is that a period of active investment will witness an increase in expenditure while the capital goods are being constructed, so that little is left to offset the depressing effect of the increased output when it materializes." (VC, 287)

Hence, the increased output, when completed, has a depressive effect which can only be offset if contrary short term forces operate. The fall in prices affects all (or a great number of) goods, not only those whose production capacities have been increased. Unemployment is likely to be all the more important as expectations are elastic and wages are rigid. Here, however, Hicks considers that one has to look more precisely at the effect on relative prices, since they are the determinants of individuals' real incomes. This effect will depend on the way the increase in demand for labour is financed during capital accumulation (capital-labour substitution or complementarity in the long run).

There is no reference to expectations in this part devoted to the accumulation of capital. That is most disturbing. Hicks indicated that the true dynamic of the system was awaited once capital accumulation comes in. Even though capital accumulation is not correctly anticipated by agents, one cannot tell how this failure of expectations will complement the maladjustment of plans that would have manifested itself even if capital accumulation had been correctly anticipated. Hicks does not discuss how both sources of wrong expectations go in the same direction or counteract each other. There is a presumption that the last chapter (ConclusionThe trade Cycle) will provide the answers. Here Hicks takes a defensive view that it is not possible to make a complete statement of a pure dynamic theory of economics (different from the views expressed by Keynes and his followers) and to assess its practical relevance (which would need a confrontation with an economic history of capitalism). Capital accumulation is a phenomenon characteristic of a trade boom. The description of the boom involves expectations once the process of quick capital accumulation is already launched.

\begin{abstract}
"If anything happens to stimulate the rate of investment by entrepreneurs (what that 'anything' may be, we will leave over for the moment), we have seen just how we should expect things to work out. There will be, first of all, a period of 'preparation', whose only visible effects are (perhaps) a small increase in the demand for factors and (perhaps) a small increase in the demand for money. If (as is usually the case at the beginning of a boom) there already exists a plethora of unemployed labour and a plethora of unemployed money, these increased demands will have practically no effect upon prices in general, and practically no effect on interest rates. The only prices which are likely to be affected are those which are the direct expression of a change in the expectations of the most sensitive persons trading - such as the prices of ordinary shares." (295)
\end{abstract}

\footnotetext{
${ }^{33}$ The present value of their future assets minus the present value of their liabilities has increased.
} 
In a second phase, once new capital goods are produced, there will be a general increase in factor demand, a rise in prices, and

"within a little, we may suppose that some industrialists may have had time to develop elastic expectations (at least for that length of time in the future which is mainly relevant for the sorts of production processes in which they are engaged); this would induce a considerable secondary fall in unemployment due to the rise in price expectations." (VC, 296)

The boom will continue through a gradual spreading of expectations ("more and more price expectations become elastic") involving new processes of accumulation; until at some point wage-earners expectations become elastic too in view of the general increase in prices. Fear that money credit to finance the boom may become rare induces soon an increase in long-run interest rate expectations, which creates the rise in long-run rates.

Hicks seems to hesitate to recourse to purely autonomous external phenomena, such as a sense of the business men that a boom has come to an end and that expectations must be reversed. The idea that accumulation of capital leads by itself to booms and slumps is accepted. However, expectations on credit paly their part too.

"Expectations of some important sections of the community prove very stubbornly inelastic, so that demand for goods in general fails to expand as rapidly as the more sensitive people had expected it to expand. This may force them, after a time, to revise their expectations downwards; but if ... the division between sensitive and insensitive people corresponds more or less to a division between people using different banking systems (that is to say, different kinds of money), the check due to this cause may be transmuted into a check through credit restriction, brought about in order to keep the different kinds of money at par." (VC, 297)

The game of expectations in cycles is acknowledged indirectly as acting upon credit restriction, based upon manifestly not substitutable kinds of money. The most important braking factor is the completion of the capital accumulation processes planned in previous periods, carrying with it its depressing influence through expectations. The cessation of accumulation by itself is sufficient

\footnotetext{
"to produce the typical slump phenomena-downward revision of expectations, leading at once to a fall in ordinary shares; shift of demand from commodities and factors to money and fixed-interest securities, leading to a fall in prices, a rise in unemployment, and (after an initial period of stringency, due to distress borrowing), a fall in interest rates. If all prices were equally flexible, and all price-expectations equally flexible, mere cessation of accumulation would be sufficient to produce a slump without a bottom - the instability of capitalism declaring itself in complete break-down."(VC, 297)
}

And Hicks goes on.

\footnotetext{
"That this does not happen is due to price-rigidities, and ultimately, beyond pricerigidities, to people's sense of normal prices. If wage-rates had risen sharply in the last stages of the boom, they may fall again fairly quickly; but this does not necessarily mean that the expectations of wage earners have become permanently elastic - it may mean no more than a relapse into the old idea of normal prices. Once these norms are re-established, they will impose a limit to the fall in wages, a point at which wages will stick. Similarly, when prices have fallen to a certain extent, there will be some entrepreneurs (those whose expectations are less elastic) who will begin to think that the prices which have now been reached are abnormally low, and who will therefore
} 
begin to develop production plans on the basis of a probability of rising prices in the future. It is these things which check the slump, which prevent the depression from developing at once into a break-down." (VC, 298)

This sense of normal prices is a factor of stability, which by itself can fail to work smoothly and efficiently to "save the situation" if no sign of recovery takes place that would induce a genuine process of accumulation. Norms of prices are by themselves liable to be disturbed by a prolonged slump (implying a revision of expectations), the destruction of norms being all the more dangerous for the economy.

Eventually, this final chapter of Value and Capital introduces two kinds of cycles. One kind is shaped by credit restriction and the other type is shaped by autonomous changes in people's beliefs and expectations. In the former case, some investment opportunities will manifest themselves easily as soon as normal prices and wages are restored. In the latter case of "natural death", recovery awaits an "entirely new factor," (VC, 299) that is, innovations (in the sense of any structural change of productive process, product or tastes). ${ }^{34}$

\title{
5. Elements towards a theory of expectations in Value and Capital
}

On the basis of this long trip through Hicks' work in the 1930s, we can try to build a Hicksian theory of expectations. Fundamentally, it is remarkable that Hicks does not venture to provide a complete microeconomic theory of the formation of expectations in Value and Capital. Nor does he provide us with a mathematical formula about the dynamics of expectations. He would certainly reject both as too mechanistic, disconnected from psychological and other uncontrollable elements.

\begin{abstract}
It seems possible to classify three sorts of influences to which price-expectations may be subject. One sort is entirely non-economic: the weather, the political news, people's state of health, their 'psychology'. Another is economic, but still not closely connected with actual price-movements; it will include mere market superstitions, at the one extreme, and news bearing on future movements of demand or supply (e.g. crop reports), at the other. The third consists of actual experience of prices, experience in the past and experience in the present; it is this last about which we can find most to say" (VC, 204)
\end{abstract}

The first two sorts of influence on price expectations are regarded as autonomous, and "we cannot hope of doing anything about it" (Value and Capital, 1939, 204). It is interesting, though, to mention that psychology is left out of the economist' knowledge, in conformity with the Paretian view.

This should not prevent us from synthesizing the various parameters that are relevant for thinking about the pattern of expectations and their role in the Hicksian dynamic of economics. As will be seen, all the elements advanced by Hicks are not strictly connected.

First of all, at the purely microeconomic level, individual's expectations are connected with the perception of risk and, we would say, are part of the theory of behaviour under risk. ${ }^{35} \mathrm{On}$ several occasions, Hicks points to the fact that individuals' choices-Hicks does not refer to "rational behaviour" - are fundamentally planning choices over a time horizon. The time horizon that human beings are able to monitor is extremely limited and variable, because it is subject to their perceptions about risk, a perception that is as much of a collective kind as of an individual kind. Any theory of expectations should start with this fact that the relevant span of

\footnotetext{
${ }^{34}$ Here Hicks describes a process of creative destruction. The schedule of innovation could determine a cycle: "A moderate degree of irregularity in the supply [of innovations] will be sufficient to generate a cycle." (Hicks, 1939, 300).

${ }^{35}$ Note that Hicks (1931) had proposed a synthesis of a theory of the entrepreneur in which all situations can be framed as a risky situation (with given probabilities).
} 
expectations (those that really make sense to individuals' decisions) is variable and can even change during the dynamic process. This was already at stake in Hicks' discussion about the time horizon of the production plan. "The length of time for which an entrepreneur will be prepared to plan ahead depends partly upon technical conditions ... but it also depends, in a very important way, on risk." (Hicks, 1393, 225). Expectations are not just calculus of probabilities, they are also principles about how to use them in various environment; they are expectations on risk and the spread of risk, not just on prices, but those non-price aspects are not fully integrated in the process or argumentation, they are not part of the model.

In the short- and long-run, additional considerations on risk and the usual range of fluctuations of interest rates tend to annihilate the effects of variations in interest rates.

\begin{abstract}
"Interest is too weak for it to have much influence on the near future; risk is too strong to enable interest to have much influence on the far future; what place is left for interest between this opposing perils? How far it can find a place depends upon the strength of the risk factor; and that, as we have seen, is largely a psychological question. In a state of grave mistrust, people will leave 'from hand to mouth'; if they do so, changes in the rate of interest can have little influence on their conduct. In a state of confidence, on the other hand, risk-allowances are much smaller; and a space will probably be left between the extremes where interest is ineffective, within which it can have a significant influence." (VC, 226)
\end{abstract}

The connection between laws of expectations and risk is in itself an argument for an autonomous theory of expectations, as the return (and distribution) on investments will be variable within a dynamic economy, two fundamental aspects for the valuation of risk according to Hicks. However, we can but note that Hicks does not rely on his previous consideration about risk in explaining the trade cycle. ${ }^{36}$

At the microeconomic level, agents' pattern of expectations is also shaped by the institutional framework of capitalism. To Hicks, eagerness towards profit will account for the fluctuations of economic activity. ${ }^{37}$

On the basis of what Hicks says about the revision of expectations, we can see the difficulty to provide a fully-fledged model of them. The representation of expectations is conceived in relation to a situation where expectations are neutral. Hicks considers that the benchmark is some model in which past prices are data and consequently, current price expectations are data too. As he puts it, in this case, "the change in current price does not disturb price expectations, it is treated as quite temporary." (VC, 204-205).

This proposition is perplexing: if past prices are dominant in determining the price expectation, it means that price expectations are based on a weighted average of past prices, but current prices will necessarily integrate this formulae in the future and there is no reason why they should be ignored currently. Hicks considers that putting all the weight on past prices is a way to express that they dominate. Whereas once they "cease to be completely dominant, we have to allow for some influence of current prices on expectations" (VC, 204-205) ${ }^{38}$ Hicks does not explain how to account for elasticities of expectations greater than 1 or negative, since both cases would require a reference to a trend based on several prices. This shows actually that

\footnotetext{
${ }^{36}$ The same applies to the household, who according to Hicks, cannot know precisely what his/her preferences would be in any near or remote future. He compensates this with the idea that household are not completely ignorant of the main features of their preferences in the future, expecting their current desires to maintain in the future, and eventually planning some consumption that are structurally important to them, without being irreversible and implying any detail about their future plans (VC, 229).

37 About agent's rationality, the entrepreneur's rationality is at stake particularly as far as joint-stock companies are concerned, since no clear principle about dividend policy can be set out (Hicks, 1939, 244)

${ }^{38} \mathrm{He}$ also suggests that the effect of a change in current prices on expectations will be uniform, so that it will not influence to a different extent price expectations at different dates.
} 
a current price that differs from expectations will be integrated in the future index of the normal price as if it had been an expected value. ${ }^{39}$ Conceiving a coherent model of expectation formation is not possible along Hicks' line of thought, because the overall idea of a normal price reduces the modelling possibilities.

To Hicks, that elasticities of expectations do not proceed from a common model is not a weakness of his theory; what is important is that they can be used to describe the properties of a dynamic economy.

\begin{abstract}
"As soon as we take elasticity of expectations into account, the stability of the system is seriously weakened. ... It is henceforth not at all surprising that the economic system of reality should be subject to large fluctuations, nor that these fluctuations should be so very dangerous" (VC, 256).
\end{abstract}

Now, I uphold that those weaknesses in Hicks microeconomic theory of expectations must be balanced with his views about the heterogeneity of expectations within a population. Hicks's conception of General Equilibrium theory is not conceived as disconnected from some socioeconomic and institutional settings (it is not supposed to be a self-sustained system). On the contrary, its properties have to be enlightened by some features of capitalist economies. To Hicks, heterogeneity among agents, be it heterogeneity in wealth, resources, or in socioeconomic roles, is a constructive element of his theory.

We have seen this throughout recurring when dealing with stability, income effects, and group reactions to price changes. This heterogeneity also applies to expectations. Households do not necessarily plan over the same time horizon and with the same time sensitivity as entrepreneurs do. As far as the time structure of the economy is concerned, for instance, individuals with a profile of lenders are made better off by a rise in the rate of interest while borrowers (usually entrepreneurs) are made worse off. Their expectations here can play a destabilizing role, since it is "inside people's heads (and not very definite even there)" (VC, 47). If their sensitivity to their own expectations differ, this can by itself generate a further disequilibrium in plans. Also, they differ in the fact that they react with various speeds to a change in the rate of interest, thus "for the market as a whole, a rise in the rate of interest will reduce current expenditure, a fall in the rate of interest increase it" (VC, 235).

Eventually in the final chapters of Value and Capital, accumulation comes in as a supplementary justification for the incompatibility of plans and the necessity to run a new process of temporary equilibrium. Unfortunately, as we have seen, Hicks does not discuss the role of expectations relatively to accumulation and decumulation of capital until he tackles the trade cycle. He does not tell us how to disentangle the role of expectations during the temporary equilibrium process from the role of expectations linked with new information about capital accumulation. A simple reason, we uphold, is that it is not possible to establish a clear-cut distinction. During the trade cycle, expectations seem to be narrowly determined by technological possibilities and by the idea of normal prices. Again, to know if normal prices are to work as stabilizing forces does not depend upon some autonomous understanding of expectations; rather, it depends indeed on the kind of innovations at work, a purely external element of the capitalist system.

Even if Hicks' theory about the stabilizing role of heterogeneity is not worked out in detail, it is probably toward this kind of explanatory scheme that Hicks is pointing out in Value and Capital, and not towards a purely autonomous theory of the formation of expectations based on past values of prices and interest rates. As we have seen throughout the article, the diversity among agents' expectations and behaviours is linked to their wealth, to their position in the productive process (as entrepreneurs or wage-earners), and to the kind of business in which

\footnotetext{
${ }^{39}$ On the modelling of adaptive expectations, see Gertchev (2007)
} 
they are involved (with a differentiated knowledge of the economy and of prices). In this respect, Hicks' project in Value and Capital reflects a representation of the laws of a capitalist economy as rooted in the heterogeneity among groups of agents participating in this economy.

\section{References}

Arrow, K. J., and Nerlove M. [1958], A Note on Expectations and Stability, Econometrica, 26(2): 297-305

Autume, Antoine (d'). [1986], Les anticipations rationnelles dans l'analyse macroéconomique, Revue d'économie politique, 37(2) : 243-281

Béraud, A. [2014], Le développement de la théorie de l'équilibre général. Les apports de Allais et de Hicks, Revue économique, 65(1): 125-158.

Bliss, C. [2008], Hicks on General Equilibrium and Stability. In Harald Hagemann and Omar Hamouda (eds), The Legacy of Sir John Hicks. His Contributions to Economic Analysis, 87-95. London: Routledge

Bliss, C. [2008], Hicks and the emptiness of general equilibrium theory. In Roberto Scazzieri, Amartya. Sen and Stefano Zamagni (eds), Markets, Money and Capital, Hicksian Economics for the Twenty-first Century, Cambridge, Cambridge University Press, 129-145

Boianovsky, M., and Trautwein, H.-M. [2006], Wicksell after Woodford, The European Journal of the History of Economic Thought, 28(2): 171-185

Chipman, J. S., and Lenfant J.-S. [2002]. Slutsky's 1915 article: How it Came to be Found and Interpreted, History of Political Economy, 34(3): 553-597.

Dasgupta, A. K. [1972], John Hicks, the New Nobel Laureate in Economics, Economic and Political Weekly, 7(48): 2315-2316.

De Vroey, M. [2006], The temporary equilibrium method: Hicks against Hicks, European Journal of the History of Economic Thought, 13(2): 259-278

Fisher, I. [1920], The Purchasing Power of Money. Its Determination and Relation to Credit, Interest and Crises (first ed. 1911), New York, The MacMillan Company 57

Fisher, I. [1933], The Debt Deflation Theory of Great Depressions, Econometrica, 1(4): 337-

Fontana, G. [2004], Hicks on monetary theory and history: money as endogenous money, Cambridge Journal of Economics, 28(1): 73-88

Glasner, David. 2018. Hayek, Hicks, Radner and the Three Equilibrium Concepts: Sequential, Temporary, and Rational Expectations. Working paper.

Gertchev, Nikolay. 2007. A Critique of Adaptive and Rational Expectations. Quarterly Journal of Austrian Economics, 10(3): 313-329

Grandmont, Jean-Michel. 1977. Temporary General Equilibrium Theory. Econometrica, 45(3): 535-572

Hahn, Frank. 1990. John Hicks the Theorist. The Economic Journal, 100(401): 539-549

Hayek, Friedrich A. von. [1928] 1984. Intertemporal Price Equilibrium and Movements in the Value of Money. [Das intertemporale Gleichgewichtssystem der Preise und die Bewegungen des "Geldwertes"]. In Money, Capital and Fluctuations: Early Essays, 71-117. London: Routledge. Weltwirtschaftliches Archiv, 28: 33-76.

Hansson, Björn A. 1982. The Stockholm School and the Development of Dynamic Method. London: Routledge.

Hayek, Friedrich A. von. 1931. Prices and production. London: George Routledge \& Sons.

Hicks, John R. 1931. The Theory of Uncertainty and Profit. Economica. 32(2): 170-189

Hicks, John R. 1932. The Theory of Wages. London: Macmillan \& Co.

Hicks, John R. [1933] 1980. Equilibrium and the Trade Cycle. Economic inquiry, 18(4): 523-534 
Hicks, John R. 1934. [Review of] Beiträge zur Geldtheorie, by F. A. von Hayek. Economica, 1(4): 479-486 1-19

Hicks, John R. 1935a. A Suggestion for Simplifying the Theory of Money. Economica, 2(5):

Hicks, John R. 1935b. Wages and Interest: The Dynamic Problem. The Economic Journal, 45(179): 456-468

Hicks, John R. 1936. Keynes’ Theory of Employment. The Economic Journal, 46(182): 238253

Hicks, John R. 1937. Mr. Keynes and the Classics; A Suggested Interpretation. Econometrica, 5(2): 147-159.

Hicks, John R. 1939. Value and Capital. An Inquiry into Some Fundamental Principles of Economic Theory. Oxford: Oxford University Press

Hicks, John R. 1973a. Recollections and documents. Economica, N.S. 40(157): 2-11

Hicks, John R. 1973b. Capital and Time. A Neo-Austrian Theory. Oxford: Clarendon Press.

Hicks, John R. 1979. The Formation of an Economist. PSL Quarterly Review, 32(130): 195204

Hicks, John R. 1985. Methods of Dynamic Economics. Oxford: Clarendon Press

Hicks, John R., and Roy D. Allen. 1934. A Reconsideration of the Theory of Value, Parts I and II. Economica, N.S., I(1): 52-76 and 1(2): 196-219.

Ingrao, Bruna and Giorgio Israel. [1987] 1990. The Invisible Hand. Economic Equilibrium in the History of Science. MIT Press.

Keynes, John Maynard. 1921. A Treatise on Probability. London: MacMillan

Keynes, John Maynard. 1930. A Treatise on Money. London: Macmillan

Keynes, John Maynard. 1936. The General Theory of Employment, Interest and Money. London: MacMillan

Keynes, John Maynard. 1937. The Ex-ante Theory of interest. The Economic Journal. 47(188): 663-669

Knight, Frank H. 1921. Risk, uncertainty and Profit. Boston and New York: Houghton Mifflin Company

Knight, Frank H. 1933. Capitalistic Production, Time and the Rate of Return. In Essays in Honour of Gustav Cassel, 327-342. London: George Allen and Unwin

Kregel, Jan A. 1977. On the Existence of Expectations in English Neoclassical Economics. Journal of Economic Literature, 15(2): 495-500

Lachmann, Ludwig M. 1945. A Note on the Elasticity of Expectations. Economica, 12(48): 248-253

Laidler, David. 1999. Fabricating the Keynesian Revolution. Studies of Inter-war literature on Money, the Cycle and Unemployment. Cambridge: Cambridge University Press.

Leijonhufvud, Axel. 1984. Hicks on Time and Money. Oxford Economic Papers, 36 (Suppl.): 26-46

Lenfant, Jean-Sébastien. 2006. Complementarity and Demand Theory: From the Twenties to the Forties. History of Political Economy, Annual Supplement: Agreement on Demand, 38(5): 48-85

Lenfant, Jean-Sébastien. 2018. Substitutability and the Quest for Stability. Some Reflections on the Methodology of General Equilibrium in Historical Perspective. HAL Archives ouvertes. https://hal.archives-ouvertes.fr/hal-01764115

Lenfant, Jean-Sébastien, and Jérôme Lallement. 2004. L'équilibre général comme savoir: de Walras à nos jours. Projet de recherche, ACI du CNRS "Histoire des savoirs", mai 2004.

Lerner, Abba P. 1940. Professor Hicks' Dynamics. Quarterly Journal of Economics, 54(2): 298-306

Lindahl, Erik. 1929. [Review of] Dynamic Pricing. The Economic Journal, 39(153): 89-91 
Lindahl, Erik. 1933. The Concept of Income. In Essays in Honour of Gustav Cassel, 399407. London: George Allen and Unwin

Lindahl, Erik. 1939. The dynamic approach to economic theory, part 1. In Studies in the Theory of Money and Capital, 21-73. London: George Allen \& Unwin

Metzler, Lloyd A. 1944. Stability of Multiple Markets: The Hicks Conditions. Econometrica, 13(4): 277-292

Myrdal, Gunnar. [1927] 1933. Der Gleichgewichtsbegriff als Instrument der geldtheoretischen Analyse. In Friedrich A. von Hayek (ed.) Beiträge zur Geldtheorie, 361-485. Vienna: Julius Springer

Peart, Sandra J. 1991. Sun Spots and Expectations: W. S. Jevons and the Theory of Economic Fluctuations. Journal of the History of Economic Thought, 13(2): 243-6

Robbins, Lionel. 1932. An Essay on the Nature and Significance of Economic Science. London: Macmillan

Rubin, Goulven. 2011. Hicks et l'économie de la dépression. Recherches économiques de Louvain / Louvain economic review, 77(4): 57-87.

Samuelson, Paul A. 1941. The Stability of Equilibrium: Comparative Statics and Dynamics. Econometrica, 9(2): 97-120

Samuelson, Paul Antony. 1944. The Relation between Hicksian Stability and True Dynamic Stability. Econometrica, 12(3-4): 256-7

Walras, Léon. [1874-1877] 1988. Eléments d'économie politique pure. Paris: Economica

Wicksell, Knut J. G. [1898] 1936. Interest and prices. A study of the causes regulating the value of money. London: Macmillan

Wicksell, Knut J. G. [1901-1906] 1934-1935. Lectures on political economy. London: George Routledge \& Sons

Wolfe, James Nathaniel. 1956. Marshall and the trade Cycle. Oxford Economic Papers, 8(1): 90-101 